\title{
Morphological Correlates of Bilateral Synchrony in the Rat Cerebellar Cortex
}

\author{
C. I. De Zeeuw, ${ }^{1,2}$ E. J. Lang, ${ }^{1}$ I. Sugihara, ${ }^{1}$ T. J. H. Ruigrok, ${ }^{2}$ L. M. Eisenman, ${ }^{4}$ E. Mugnaini, ${ }^{3}$ and R. Llinás ${ }^{1}$ \\ 1 Department of Physiology and Neuroscience, New York University Medical School, New York, New York 10016, \\ 2 Department of Anatomy, Frasmus University Rotterdam. The Netherlands, 3institute of Neurnscience, Northwestern \\ University, Chicago, Illinois 60611, and ${ }^{4}$ Daniel Baugh Institute of Anatomy, Jefferson Medical College, Thomas Jefferson \\ University, Philadelphia, Pennsylvania 19107
}

Simultaneous recordings of the left and right crus IIA of the cerebellar cortex in the rat have demonstrated that Purkinje cells of both sides can be activated synchronously by their climbing fibers. Because climbing fibers arise exclusively from the contralateral inferior olive $(\mathrm{IO})$, this physiological finding seems to contradict the anatomy. To define the structural basis responsible for the bilateral synchrony, we examined the possibilities that bilateral common afferent inputs to the 10 and interolivary connections form the underlying mechanisms.

The bilaterality of the major afferents of the olivary regions that project to crus IIA was studied using Phaseolus vulgaris leucoagglutinin as an anterograde tracer. We found that the excitatory and inhibitory projections from the spinal trigeminal nucleus and dorsolateral hump of the interposed cerebellar nucleus to the transition area between the principal olive and dorsal accessory olive were bilateral.

A second possible mechanism for bilateral synchrony, which is the possibility that axons of olivary neurons provide collaterals to the contralateral side, was investigated using biotinylated dextran amine as an anterograde tracer. Labeled axons were traced and reconstructed from the principal olive and dorsal and medial accessory olive up to the entrance of the contralateral restiform body. None of these axons gave rise to collaterals.

The possibility that neurons in the left and right 10 are electrotonically coupled via dendrodendritic connections was investigated by examining the midline region of the 10 . The neuropil of the left and right $I O$ is continuous in the dorsomedial cell column. Examination of Golgi impregnations of this subdivision demonstrated that (1) many dendrites cross from one side to the other, (2) neurons close to the midline give rise to dendrites that extend into both olives, and (3) dendrites of neurons in the dorsomedial cell column frequently traverse into adjacent olivary subdivisions such as the medial accessory olive and the transition area between the principal olive and dorsal accessory olive. Sections immunostained for dendritic lamellar bodies or GABAergic terminals showed the same pattern: the neuropils of the dorsomedial cell columns on both sides form a continuum with each other as well as with the neuropil of other adjacent olivary subdivisions. Ultrastructural examination of the dorsomedial cell column demonstrated that the midline area includes many complex glomeruli that contain dendritic spines linked by gap junctions.

To verify whether the complex spike synchrony observed between left and right crus \|A could indeed be mediated in part through coupled neurons in the dorsomedial cell column, we recorded simultaneously from crus IIA areas and from left and right vermal lobule IX, which receives climbing fibers from the dorsomedial cell column. In these experiments we demonstrated that the climbing fibers of all four areas, i.e., the left and right crus IIA as well as the left and right lobule IX, can fire synchronously.

The present results indicate that synchronous climbing fiber activation of the left and right crus IIA in the rat can be explained by (1) bilateral inputs to the transition areas between the principal olive and dorsal accessory olive and (2) dendrodendritic electrotonic coupling between neurons of the left and right dorsomedial cell column and between neurons of the dorsomedial cell column and adjacent olivary subdivisions.

Key words: inferior olive; gap junctions; electrotonic coupling; complex spikes; dendritic lamellar bodies; dorsomedial cell column; spinal trigeminal nucleus; cerebellar nuclei; GABA
The connectivity between the inferior olive (IO) and the cerebellum is organized topographically (Groenewegen and Voogd, 1977; Groenewegen et al., 1979; Voogd and Bigaré, 1980; Flumerfelt and Hrycyshyn, 1985; De Zeeuw et al., 1994a,b). The IO consists of different subdivisions, each of which provides climbing fibers to a specific zone of Purkinje cells in the contralateral

Received Jan. 24, 1996; revised Feb. 21, 1996; accepted Feb. 27, 1996.

We thank Dr. M. Sugimori for reading the manuscript, and Mr. E. Dalm, Mr. R. Hawkins, Mr. H. van der Burg, Mrs. E. Goedknegt, and Mrs. M. Wright-Goss for technical assistance.

Correspondence should be addressed to Dr. Chris 1. De Zeeuw, Department of Anatomy, Erasmus University Rotterdam, P.O. Box 1738, 3000 DR, Rotterdam, The Netherlands.

Copyright $\odot 1996$ Society for Neuroscience $\quad 0270-6474 / 96 / 163412-15 \$ 05.00 / 0$ cerebellar cortex, and each zone of Purkinje cells innervates a specific cerebellar and/or vestibular nucleus that in turn projects to the corresponding olivary subdivision. Neurons in the olivary subdivisions seem to be grouped in separate clusters, with their dendritic fields usually being restricted to a particular subdivision (Ramon y Cajal, 1909; Scheibel and Scheibel, 1955, 1956; Bowman and King, 1973; Sotelo et al., 1974; Gwyn et al., 1977; Rutherford and Gwyn, 1980; Foster and Peterson, 1986; Iwahori and Kiyota, 1987; Szteyn, 1988; Ruigrok et al., 1990a). Because of the limited territories of the olivary dendrites and the precise topographic organization of the olivocerebellar system, the different olivary subdivisions generally are considered as separate and distinct functional entities (Oscarsson, 1980). 
These functional entities also are reflected in the spatiotemporal patterns of climbing fiber activation [i.e., complex spikes (CSs)] that can be observed with the use of multiple simultancous recordings from Purkinje cells (Llinás and Sasaki, 1989; Sasaki et al., 1989; Wylie et al., 1995). The CSs of particular sagittal strips of Purkinje cells tend to occur rhythmically and almost simultaneously. This close temporal correlation between CSs is attributable to (1) the intrinsic electroresponsive properties of olivary neurons (Llinás and Yarom, 1981a,b, 1986), (2) the electrotonic coupling of olivary neurons (Llinás, 1974; Llinás et al., 1974; Llinás and Yarom, 1981a) by dendrodendritic gap junctions (cat: Sotelo et al., 1974; De Zeeuw et al., 1989; opossum: King, 1980; guinea pig: Benardo and Foster, 1986; monkey: Rutherford and Gwyn, 1977; rat: Sotelo et al., 1986; Angaut and Sotelo, 1989; De Zeeuw et al., 1990c; rabbit: De Zeeuw et al., 1993), and (3) the isochronicity of the conduction times of olivary axons (Sugihara ct al., 1993; Aggelopoulos et al., 1994). As originally proposed by Llinás (1974), the efficacy of the coupling between olivary neurons is not static, but probably mainly controlled by inhibitory synaptic inputs. GABAcrgic tcrminals from the cerebellar nuclei are apposed to glomerular dendrites coupled by gap junctions (Nelson et al., 1984; Anguat and Sotelo, 1989; De Zeeuw et al., 1989; Fredette and Mugnaini, 1991), and systemic or local application of GABA-antagonists and/or lesions of the cerebellar nuclei increase the synchrony between olivary neurons (Llinás and Sasaki, 1989; Lang et al., 1989, 1990, in press). The importance of electrotonic coupling for the olivocerebellar system is supported further by the distribution of dendritic lamellar bodies that can be associated with dendrodendritic gap junctions; these dendritic lamellar bodies are distributed ubiquitously in all olivary subdivisions, and their density in the IO is higher than in any other area of the brain (De Zeeuw et al., 1995a).

Recently, bilateral recordings of crus IIA in the rat demonstrated that CS synchrony is not restricted to Purkinje cells of a single zone but can also occur between Purkinje cells on both sides of the brain (Fukuda et al., 1987; Lang et al., in press). This bilateral synchrony is organized symmetrically and is particularly prominent after systemic or local (i.e., to the IO) administration of a GABA-antagonist such as picrotoxin or after lesions of the cerebellar nuclei. At present, it is not clear how the bilateral synchrony can be explained, because most, if not all, climbing fibers are derived from the contralateral IO (Groenewegen and Voogd, 1977; Groenewegen et al., 1979; Flumerfelt and Hrycyshyn, 1985; Tan et al., 1995).

The climbing fibers of crus IIA are derived from the contralatcral mcdial accessory olive and the transition area between the medial portions of the ventral lamella of the principal olive and the ventral fold of the dorsal accessory olive (referred to as T-area) (Azizi and Woodward, 1987; Nelson and Mugnaini, 1988; Llinás and Sasaki, 1989). To determine the morphological substrate for this bilateral synchrony in the crus IIA folia, we investigated whether these olivary subdivisions receive bilateral afferent inputs and whether these subdivisions on the left and the right side are coupled through axonal and/or dendrodendritic connections. The afferents were studied using anterograde transport of Phaseolus vulgaris leucoagglutinin (PHA-L) from the spinal trigeminal nucleus and the dorsolateral hump of the cerebellar nuclei, which are known to project to the T-area (Huerta et al., 1983, 1985; Swenson and Castro, 1983; Ruigrok and Voogd, 1990). The possible existence of olivary axon collaterals projecting to the contralateral side was investigated using biotinylated dextran amine (BDA) as an anterograde tracer. Finally, the possibil- ity that neurons in the left and right 10 have dendrodendritic connections was investigated at both the light microscopic and the clectron microscopic level by examining the midline region of the IO for the presence of crossing dendrites, dendrodendritic gap junctions, dendritic lamellar bodies, and GABAergic synaptic inputs. The results of the latter investigation demonstrated that dendrites from both dorsomedial cell columns (DMCCs) are linked by gap junctions forming an interolivary bridge sufficiently rich to support electrotonic coupling between the olives. Multiple electrode recordings were then implemented to test the hypothesis that coupling through gap junctions between neurons from the left and right DMCC contributes to the bilateral synchrony of CS activity in crus IIA.

\section{MATERIALS AND METHODS}

Anterograde tracing with PHA-L. The bilaterality of afferents to the IO was investigated with the tracer PHA-L. Four adult male Wistar rats were anesthetized with sodium pentobarbital (Nembutal, $75 \mathrm{mg} / \mathrm{kg}$, i.p.) and mounted on a stereotaxic apparatus; the occipital bone was exposed and partly removed, and the foramen magnum was enlarged. Unilateral stereotaxic injections were made in the dorsolateral hump of the cerebellar nuclei $(n=2)$ or the spinal trigeminal nucleus $(n=2)$ with a glass micropipette (tip diameter, $8-15 \mu \mathrm{m}$ ) filled with $2.5 \%$ PHA-L (Vector) in $0.05 \mathrm{M}$ Tris-buffered saline (TBS), $\mathrm{pH} 7.4$. The tracer was iontophoretically injected with a positive current $(4-8 \mu \mathrm{A})$ that pulsed $7 \mathrm{sec}$ on $/ 7 \mathrm{sec}$ off for a total of $30 \mathrm{~min}$. Afterward, the pipette was withdrawn, the wound was sutured, and the animal was allowed to recover. After a survival time of $7 \mathrm{~d}$, the animals were anesthetized with Nembutal $(200 \mathrm{mg} / \mathrm{kg})$ and perfused with $200 \mathrm{ml} 0.05 \mathrm{M}$ phosphate buffer, $\mathrm{pH} 7.4$, containing $0.8 \%$ $\mathrm{NaCl}, 0.8 \%$ sucrose, and $0.4 \% d$-glucose followed by 1 liter of fixative ( $0.5 \%$ depolymerized paraformaldehyde, $2.5 \%$ glutaraldehyde, and $4 \%$ sucrose in the same buffer). The dissected brains were kept in the same fixative for $2 \mathrm{hr}$, transferred to a $10 \%$ sucrose solution until they sank, and embedded in $10 \%$ gelatin dissolved in $10 \%$ sucrose solution. The gelatin was hardened in $4 \%$ formaldehyde for $3 \mathrm{hr}$. Subsequently, the embedded brains were transferred to $30 \%$ sucrose in phosphate buffer, $\mathrm{pH} 7.4\left(4^{\circ} \mathrm{C}\right)$, in which they were stored until they sank. Serial coronal sections $(40 \mu \mathrm{m}$ thick) of the brainstem were cut on a freezing-stage microtome and processed to reveal PHA-L (Gerfen and Sawchenko, 1984). The sections were collected, rinsed in TBS $(3 \times 15 \mathrm{~min})$, and incubated overnight in the primary antiserum (goat anti-PHA-L, Vector), diluted 1:2000 in TBS containing Triton X-100 (TBS + ) $(0.9 \% \mathrm{NaCl}, 0.2 \% / 0.4 \%$ Triton $\mathrm{X}-100$ in $0.05 \mathrm{M}$ Tris- $\mathrm{HCl}, \mathrm{pH} 8.6)$. Subsequently, the sections were rinsed in TBS $+(3 \times 15 \mathrm{~min})$, incubated for $2 \mathrm{hr}$ in rabbit anti-goat IgG (Sigma, $1: 200$ in TBS +$)$, rinsed in TBS $+(3 \times 15 \mathrm{~min})$, and incubated for $2 \mathrm{hr}$ in goat peroxidase antiperoxidase (PAP) (Nordic, 1:400 in TBS + ). Finally, the sections were rinsed in Tris- $\mathrm{HCl}(0.05 \mathrm{M}, \mathrm{pH} 7.6)$ and incubated with $0.05 \%$ 3,3'-diaminobenzidine-tetrahydrochloride (Sigma, St. Louis, MO) (DAB) and $0.01 \% \mathrm{H}_{2} \mathrm{O}_{2}$ in Tris- $\mathrm{HCl}$ for 30-45 min. After thorough rinsing in Tris- $\mathrm{HCl}$, sections were mounted, counterstained with either cresyl violet or neutral red, and coverslipped.

Anterograde tracing with $B D A$. Olivary axon collaterals were investigated with the use of anterograde tracing of BDA. Threc adult malc Wistar rats were anesthetized with sodium pentobarbital (Nembutal, 75 $\mathrm{mg} / \mathrm{kg}$, i.p.) and mounted in a stereotaxic apparatus; the dorsal surface of the brainstem was exposed. A beveled glass electrode $(16-19 \mu \mathrm{m}$ tip) filled with $10 \%$ BDA in $0.05 \mathrm{M}$ Tris buffer (TB) was placed into the IO, and olivary responses showing a characteristic $0.5-1.5 \mathrm{~Hz}$ frequency were identified. Subsequently, BDA was injected unilaterally using pulsed clectrical stimulation for $10 \mathrm{~min}(50 \%$ duty cycle at $0.25 \mathrm{~Hz},+4 \mu \mathrm{A})$.

After a survival time of $48 \mathrm{hr}$, the rats were anesthetized with an overdose of Nembutal $(200 \mathrm{mg} / \mathrm{kg})$ and perfused transcardially with 1 liter of a solution of $0.01 \mathrm{M}$ phosphate buffer and $0.9 \% \mathrm{NaCl}, \mathrm{pH} 7.4$ (PBS), 1

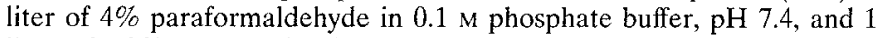
liter of $10 \%$ sucrose in the same buffer. The dissected brains were cryoprotected in $30 \%$ sucrose in PBS until they sank and then were sectioned at $40 \mu \mathrm{m}$ on a freezing microtome. All sections were collected in PBS and kept in serial order throughout the following steps. The sections were incubated in a solution of avidin-D-horseradish peroxidase $(0.2 \%)$ and $0.5 \%$ Triton X-100 (PBS-X) for 2 hr at room temperature under gentle agitation. Subscquently, the sections were rinsed three times in PBS and three times in $0.15 \mathrm{M} \mathrm{TB}, \mathrm{pH} 7.5$, reacted for $10 \mathrm{~min}$ in $0.06 \%$ 
$\mathrm{DAB}$ and $0.003 \% \mathrm{H}_{2} \mathrm{O}_{2}$ in TB, and rinsed three times in TB. The sections were counterstained with neutral red, serially mounted on slides, dried overnight, and coverslipped. The olivary axons were reconstructed serially from the injection site to their entrance into the restiform body using a light microscope equipped with a $100 \times$ oil objective and a drawing attachment.

Golgi impregnation. The IOs of four adult Sprague-Dawley rats were processed for Golgi impregnation. The rats were anesthetized with sodium pentobarbital $(75 \mathrm{mg} / \mathrm{kg}$, i.p.) and perfused through the ascending aorta with saline, followed by a buffered aldehyde fixative and then by a mordant consisting of $6 \%$ potassium dichromate, $6 \%$ chloral hydrate, and $4 \%$ formaldehyde. After postfixation in the same mordant for $3 \mathrm{~d}$, blocks of the IO were treated with $0.75 \%$ silver nitrate for an additional $3 \mathrm{~d}$ (Sotelo and Palay, 1968; Adams, 1979), embedded in a soft Epon mixture, and sectioned with a heated steel knife (Blackstad et al., 1984).

Dendritic lamellar bodies. The distribution of dendritic lamellar bodies in the olivary midline area was studied immunocytochemically using $\alpha 12 \mathrm{~B} / 18$ as the primary antiserum (for details and specificity tests, see De Zeeuw et al., 1995a). Five adult Sprague-Dawley rats were anesthetized with sodium pentobarbital $(75 \mathrm{mg} / \mathrm{kg}$, i.p.) and perfused transcardially with $200 \mathrm{ml}$ saline followed by 1 liter of $0.5 \%$ zinc salicylate, $4 \%$ freshly depolymerized formaldehyde, and $0.9 \% \mathrm{NaCl}, \mathrm{pH} 5.0$, at room temperature (Mugnaini and Dahl, 1983). The brainstem containing the IO was removed $1 \mathrm{hr}$ after perfusion and cryoprotected in saline containing $30 \%$ sucrose. The tissue was cut into $20-\mu \mathrm{m}$-thick coronal sections on a freezing microtome. All sections were collected in $0.5 \mathrm{M} \mathrm{TB}, \mathrm{pH} 7.6$, with $0.25 \%$ Triton $\mathrm{X}-100$, blocked in $5 \%$ normal donkey serum in TB, directly incubated in the primary antiserum $\alpha 12 \mathrm{~B} / 18$ diluted $1: 2000$ in $2 \%$ normal donkey serum in TB for $48 \mathrm{hr}$ on a shaker at $4^{\circ} \mathrm{C}$, thoroughly rinsed in TB, incubated for $1 \mathrm{hr}$ in goat anti-rabbit IgG (Sternberger Monoclonals) diluted 1:50 in TB, thoroughly rinsed in TB, and incubated in rabbit PAP (Sternberger Monoclonals) diluted 1:100 in TB for $1 \mathrm{hr}$, and rinsed as above. Finally, the sections were incubated for $15-20 \mathrm{~min}$ in $0.05 \% \mathrm{DAB}$ and $0.01 \% \mathrm{H}_{2} \mathrm{O}_{2}$ in $0.05 \mathrm{M} \mathrm{TB}$, mounted, and coverslipped.

GABAergic input. The GABAcrgic input to the olivary dendrites was studied at the light microscopic level using an antiserum against glutamic acid decarboxylase (GAD), the GABA-synthesizing enzyme (Oertel et al., 1981). Four Sprague-Dawley rats were anesthetized deeply with Nembutal (75 mg/kg, i.p.) and perfused transcardially with $200 \mathrm{ml}$ physiologic saline followed by 1 liter of $0.5 \%$ zinc salicylate, $4 \%$ formaldehyde, and $0.9 \% \mathrm{NaCl}, \mathrm{pH} 4.5$, at room temperature. The brainstems were removed $1 \mathrm{hr}$ after perfusion, cryoprotected in saline containing $30 \%$ sucrose, and sectioned at $25 \mu \mathrm{m}$ on a freezing-stage microtome. Immunohistochemistry was performed with a GAD antiserum raised in sheep (Oertel et al., 1981), as published previously (Nelson et al., 1989; Fredette and Mugnaini, 1991). Briefly, the sections were blocked in rabbit serum and incubated in GAD antiserum (1:2000), rabbit anti-sheep (1:50), and goat PAP (1:100). Finally, the sections were reacted in DAB and $\mathrm{H}_{2} \mathrm{O}_{2}$.

Electron microscopy. To examine the midline region of the IO for the presence of gap junctions, brainstems of two adult Sprague-Dawley rats were processed for electron microscopy according to published protocols (De Zeeuw et al., 1988). The animals were anesthetized with Nembutal $(75 \mathrm{mg} / \mathrm{kg}$, i.p.) and perfused transcardially with $100 \mathrm{ml}$ of $0.9 \%$ saline in $0.18 \mathrm{M}$ cacodylate buffer, $\mathrm{pH} 7.3$, followed by 1 liter of $5 \%$ glutaraldehyde in the same buffer. The brainstems were kept in the same fixative for $2 \mathrm{hr}$ and coronally sectioned on a Vibratome at $70 \mu \mathrm{m}$. These Vibratome sections were osmicated (in $8 \%$ glucose solution), block-stained in uranyl acetate, directly dehydrated in dimethoxypropane, and embedded in Araldite. Guided by semithin sections, we prepared pyramids of different midline areas and adjacent subdivisions such as the medial accessory olive, the T-area, the dorsal cap, the $\beta$-nucleus, and DMCC. Ultrathin sections were cut from these tissue blocks, counterstained with uranyl acetate and lcad citrate, and examined in an electron microscope operated at $80 \mathrm{kV}$. From tissue blocks containing the DMCC, some ultrathin sections were mounted on Formvar-coated nickel grids and processed for GABA-immunocytochemistry with a rabbit antiserum to a GABAglutaraldehyde conjugate (for details about the specificity of the antibody, see Seguela et al., 1984; Buijs et al., 1987). Antibody-binding sites were revealed with a goat anti-rabbit antibody (Janssen) labeled with $15 \mathrm{~nm}$ gold particles, diluted 1:40.

Multiple-unit recording. Generally, the multiple electrode technique that was used follows that described by Sasaki ct al. (1989). Threc adult Sprague-Dawley rats were anesthetized with an initial intraperitoneal injection of ketamine $(100 \mathrm{mg} / \mathrm{kg})$, Xylazine $(8 \mathrm{mg} / \mathrm{kg})$, and atropine $(0.4$ $\mathrm{mg} / \mathrm{kg}$ ). Supplemental doses of ketamine $(7 \mathrm{mg} / \mathrm{kg})$ were given through a femoral vein catheter every 30 min starting $3 \mathrm{hr}$ after the initial dose. Once the animal was anesthetized, it was paralyzed with Flaxedil (1.5 $\mathrm{mg} / \mathrm{kg}$ ) and ventilated artificially. Subsequently, its head was fixed on a stereotaxic apparatus, and the body was placed on a heating pad to maintain the rectal temperature at $36-37^{\circ} \mathrm{C}$.

After the bone and the dura overlying the cerebellum were removed, previously prepared mesh grids were cemented in place to serve as a reference frame and a holding device for the electrodes (Sasaki et al., 1989). Grids were placed over right and left lobule IXb and over both crura IIA. For each animal, as many as 88 electrodes were inserted into the cerebellum (44 on each side). Each individual electrode was (1) attached via a wax droplet to a holder that was coupled to a joy-stickcontrolled piezoelectric micromanipulator (Burleigh), (2) inserted through the grid into the molecular layer, and (3) released by melting the wax after a CS was isolated.

The electrode signals were recorded with a homemade pre- and main amplifier system consisting of 96 independent channels (Fukuda et al., 1987 ) and fed into junctional field-effect transistor elements (074, Texas Instruments). The amplifier system had a total gain of 1000 and a $500-5000 \mathrm{~Hz}$ frequency filter. The extracellularly recorded CSs were recognized by their characteristic multi-phasic wave shape and their low spontaneous frequency (Eccles et al., 1966). After amplification, the recorded CSs in each channel were converted into digital form, using a one-level threshold. The time of occurrence of a CS was defined as the beginning of its initial deflection. The threshold for the digitization was set positively or negatively depending on the direction of the initial rise. The digital signals from all channels were stored simultaneously on VCR tape and transferred into an 80386-based personal computer through a homemade interface that scanned all channels within $10 \mu$ s with a $1 \mathrm{msec}$ intersampling period. The file containing the digital signals was then transferred into a minicomputer (MicroVAX 3100, Digital Equipment) and analyzed by using homemade FORTRAN programs.

To measure the degree of synchrony between the CS activity, crosscorrelation coefficients (Gerstein and Kiang, 1960; Sasaki et al., 1989) were calculated for all possible combinations of Purkinje cell pairs. The cross-correlation cocfficient $C(t)$ cquals:

$$
\begin{gathered}
C(t)=\sum_{i=1}^{N}\{V(i) W(i+t)\} /\left[\sum_{i=1}^{N} V(i)^{2} \sum_{i=1}^{N} W(i)^{2}\right]^{1 / 2} \\
V(I)=X(i)-\sum_{i=1}^{N} X(i) / N, \quad W(i)-Y(i)-\sum_{i=1}^{N} Y(i) / N
\end{gathered}
$$

In this formula, $V(i)$ is the normalized form of $X(i)$, which represents the spike train of the "master" cell of the Purkinje ceil pair ( $i$ represents the time step: $i=1,2, \ldots, N) . X(i)=1$, if the onset of a CS occurs in the $i$ th bin; if not $X(i)=0 . W(i)$ and $Y(i)$ are the same as $V(i)$ and $X(i)$, respectively, but for a compared cell. In the present study, a $1 \mathrm{msec}$ time bin was used to define synchrony. The zero-time cross-correlation coefficient $C(0)$ represented the degree of synchrony. The synchrony was tested during spontaneous activity and after systemic application of picrotoxin (dose: 1 $\mathrm{mg} / \mathrm{kg}$, dissolved $1 \mathrm{mg} / \mathrm{ml}$ saline, administered $0.3 \mu \mathrm{l} / \mathrm{min}$, i.v.).

\section{RESULTS}

In the present study, we explored possible mechanisms to explain the bilateral synchrony of CS activity in the rat cerebellar cortex. Threc possibilities were considered: (1) bilateral olivary afferent inputs; (2) axonal interolivary projections; and (3) interolivary dendritic connections. The first and second possibilities were investigated with the use of anterograde tracers (PHA-L and BDA), whereas the third hypothesis was studied using different light microscopic and electron microscopic methods and bilateral multiple-unit recordings.

\section{Anterograde tracing with PHA-L}

The bilaterality of afferents to the IO was investigated using anterograde transport of PHA-L from the dorsolateral hump of the cerebellar nuclei and the spinal trigeminal nucleus. The iontophoretic injections of PHA-L appeared as dark brown-stained areas that contained numerous darkly stained cell bodies. An- 

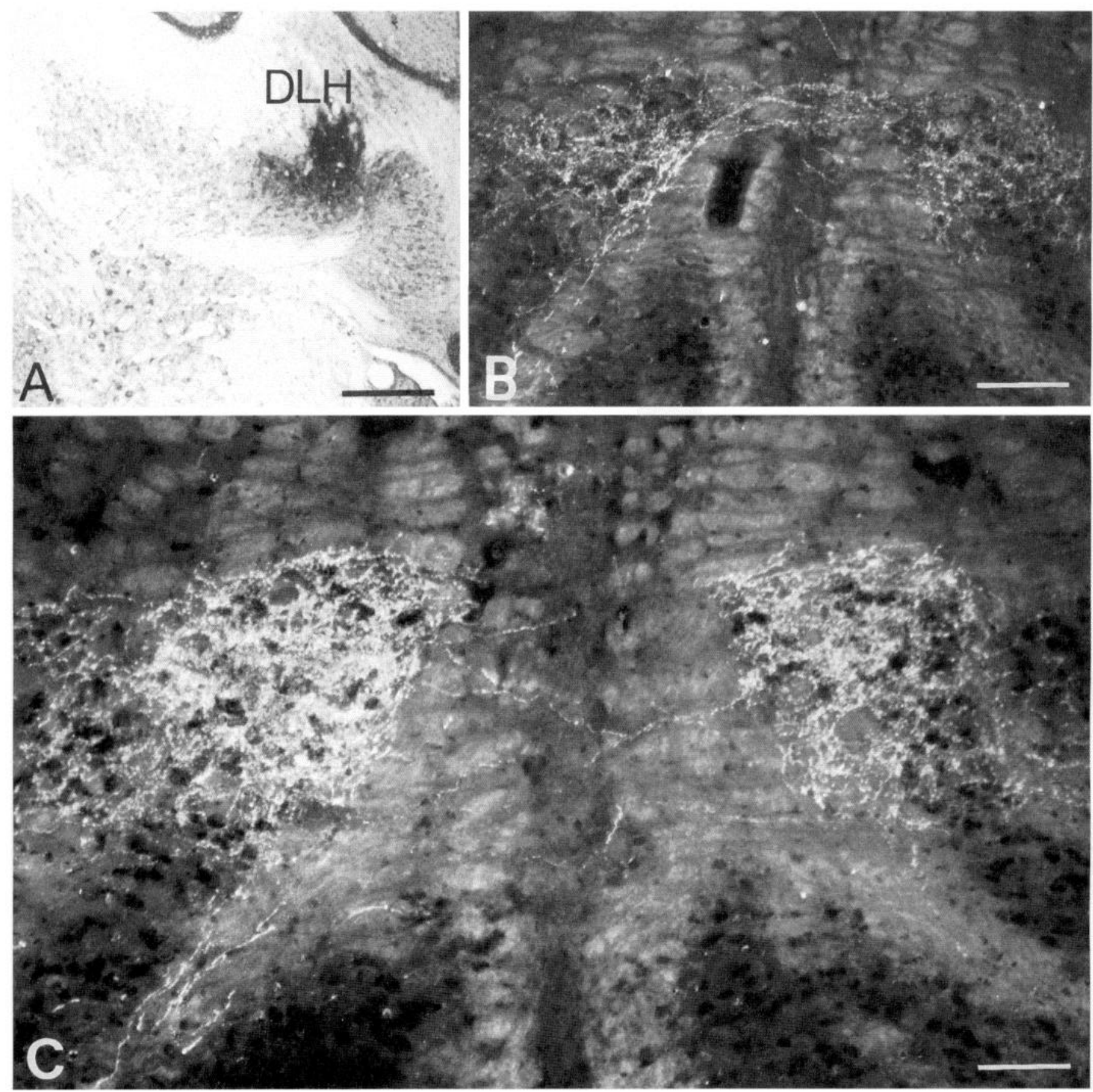

Figure 1. Unilateral injection of PHA-L in the dorsolateral hump $(D L H)$ of the interposed cerebellar nucleus $(A)$ and bilateral projection in the T-area of the IO $(B, C)$. Note the symmetry and the density of the anterograde labeling. Scale bars: $A, 500 \mu \mathrm{m} ; B, 150 \mu \mathrm{m} ; C, 80 \mu \mathrm{m}$.

terograde transport of PHA-L resulted in complete labeling of preterminal and terminal fibers, which showed varicosities and intervaricose segments. In two cases, the injections sites were centered on the dorsolateral hump (Fig. 1A). Labeled fibers left the cerebellum and ascended through the ipsilateral superior cerebellar peduncle until they reached its decussation in the tegmentum. From there the labeled fibers left the ventromedial part of the superior cerebellar peduncle, descended contralaterally in the medial tegmental bundle, and partially crossed at the level of the IO. Both the ipsilateral and contralateral olive contained numerous labeled varicosities in the
T-area (Fig. $1 B, C$ ). The projection showed a slight contralateral predominance.

In two other cases, the injections sites were centered on the pars interpolaris of the spinal trigeminal nucleus (Fig. 2A). The trigemino-olivary axons took a rather direct route to the contralateral IO. They left the spinal trigeminal nucleus from its ventromedial aspect and traversed the brainstem reticular formation. Terminal varicosities were observed in various olivary subdivisions on the ipsilateral and contralateral side (Fig. $2 B$ ). The only olivary region with a bilateral input from the trigeminal nucleus was the $\mathrm{T}$-area; this projection showed a 


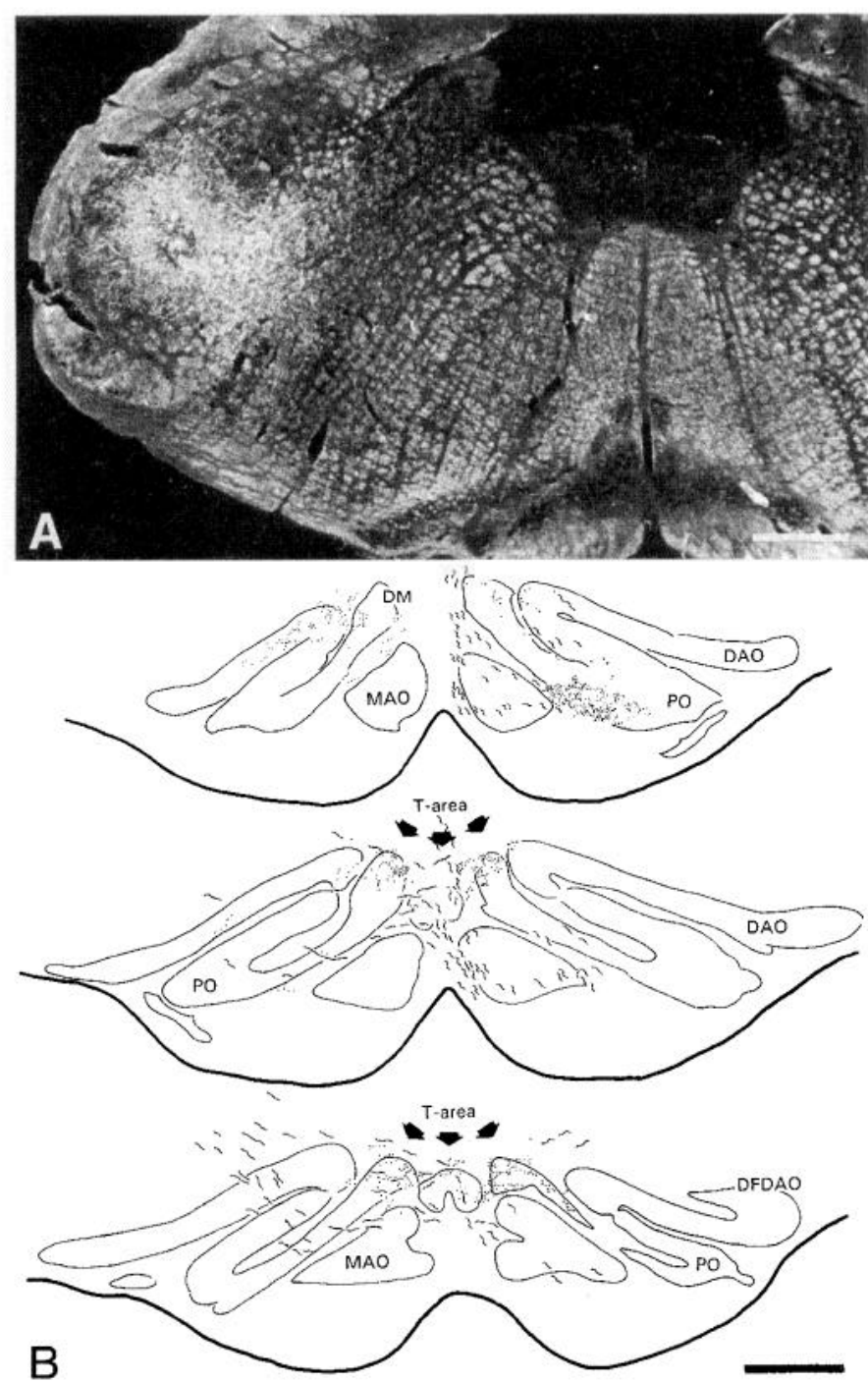

Figure 2. Unilateral injection of PHA-L in the pars interpolaris of the spinal trigeminal nucleus $(A)$ and a reconstruction of the bilateral projection in the T-area of the IO $(B)$. Projections were seen unilaterally in various olivary subdivisions such as the contralateral caudal $D A O$ (not shown) and $P O$. The T-area was the only olivary region that received a bilateral input from the trigeminal nucleus. $D M$, Dorsomedial group; $M A O$, medial accessory olive; $D A O$, dorsal accessory olive; $P O$, principal olive; $D F D A O$, dorsal fold DAO. Scale bars: $A, 460 \mu \mathrm{m} ; B, 410 \mu \mathrm{m}$.

contralateral predominance and was less dense $(\sim 40 \%)$ than that from the dorsolateral hump.

\section{Anterograde tracing with BDA}

Olivary axon collaterals were investigated with the anterograde tracer BDA. Unilateral BDA injections were made into the IO, one of which was centered in the T-area. Numerous olivary axons were labeled from the injection site up to their entrance into the restiform body; 121 axons were traced and/or reconstructed (Fig. 3). No axons were found that gave rise to collaterals to the contralateral IO. For comparison, we also analyzed some of the retrogradely labeled afferent fibers of the IO. Some of these fibers gave off very fine collaterals with varicosities in the reticular formation.

\section{Golgi impregnation}

Examination of the Golgi-impregnated brainstems demonstrated that the neuropil of the left and right IO were continuous with

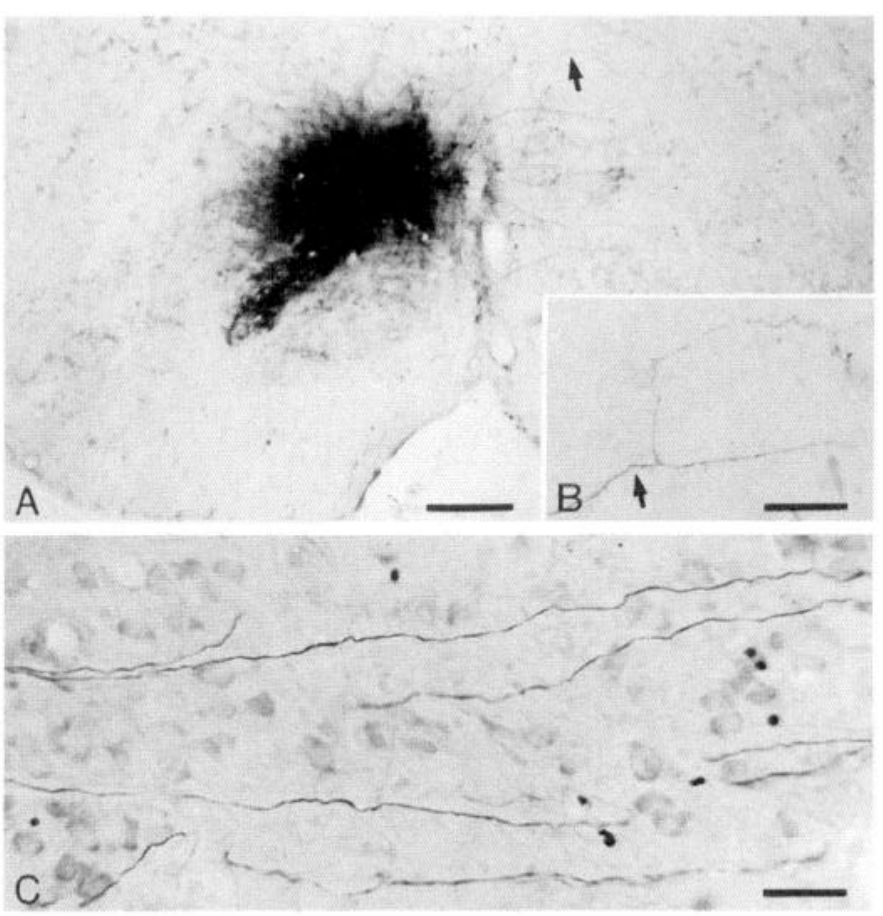

Figure 3. An injection of BDA centered on the T-area of the IO $(A)$ that provided labeled olivary axons passing through the contralateral IO $(C)$. None of these fibers gave rise to axon collaterals. $B$, In contrast, some of the retrogradely labeled fibers in the reticular formation did show collaterals. Arrows in $A$ and $B$ indicate origin of collateral in the reticular formation. Scale bars: $A, 240 \mu \mathrm{m} ; B, 59 \mu \mathrm{m} ; C, 41 \mu \mathrm{m}$.

each other at the midline in one olivary subdivision, the DMCC. In this subdivision, many dendrites $(\sim 25 \%)$ crossed from one side to the other (Fig. 4), whereas the majority of the neurons positioned at or near the midline gave rise to dendrites that entered the left IO and those that entered the right IO. In addition, dendrites of neurons in the DMCC coursed frequently into adjacent olivary subdivisions such as the medial accessory olive and the T-area. Infrequently, dendrites even crossed from the DMCC to the T-area on the other side. At other midline locations, olivary cell bodies were absent, but occasional dendrites crossed from one side to the other. Olivary axons impregnated by the Golgi-staining did not give off any axon collaterals to either the ipsilateral or the contralateral IO.

\section{Dendritic lamellar bodies}

Puncta immunostained with antiserum $\alpha 12 \mathrm{~B} / 18$, which in the electron microscope correspond to dendritic lamellar bodies (De Zeeuw et al., 1995a), were present in all olivary subdivisions. With regard to the midline region of the IO, lamellar bodies were located only in the DMCC (Fig. 5). In addition, the lamellar bodies were present at the border between the DMCC and the $\mathrm{T}$-area and at the border between the DMCC and the medial accessory olive. The density of lamellar bodies was particularly high in the periphery of the DMCC. On average, the DMCC contained seven lamellar bodies $/ 1000 \mu \mathrm{m}^{2}$ in a given plane of focus (for counting procedures see De Zeeuw et al., 1995a). The total density of lamellar bodies in a $20-\mu$ m-thick immunostained section was 21 lamellar bodies $/ 10,000 \mu \mathrm{m}^{3}$.

\section{GABAergic input}

GAD-immunostained sections of the IO showed that the GABAergic afferents of the IO followed the distribution pattern 

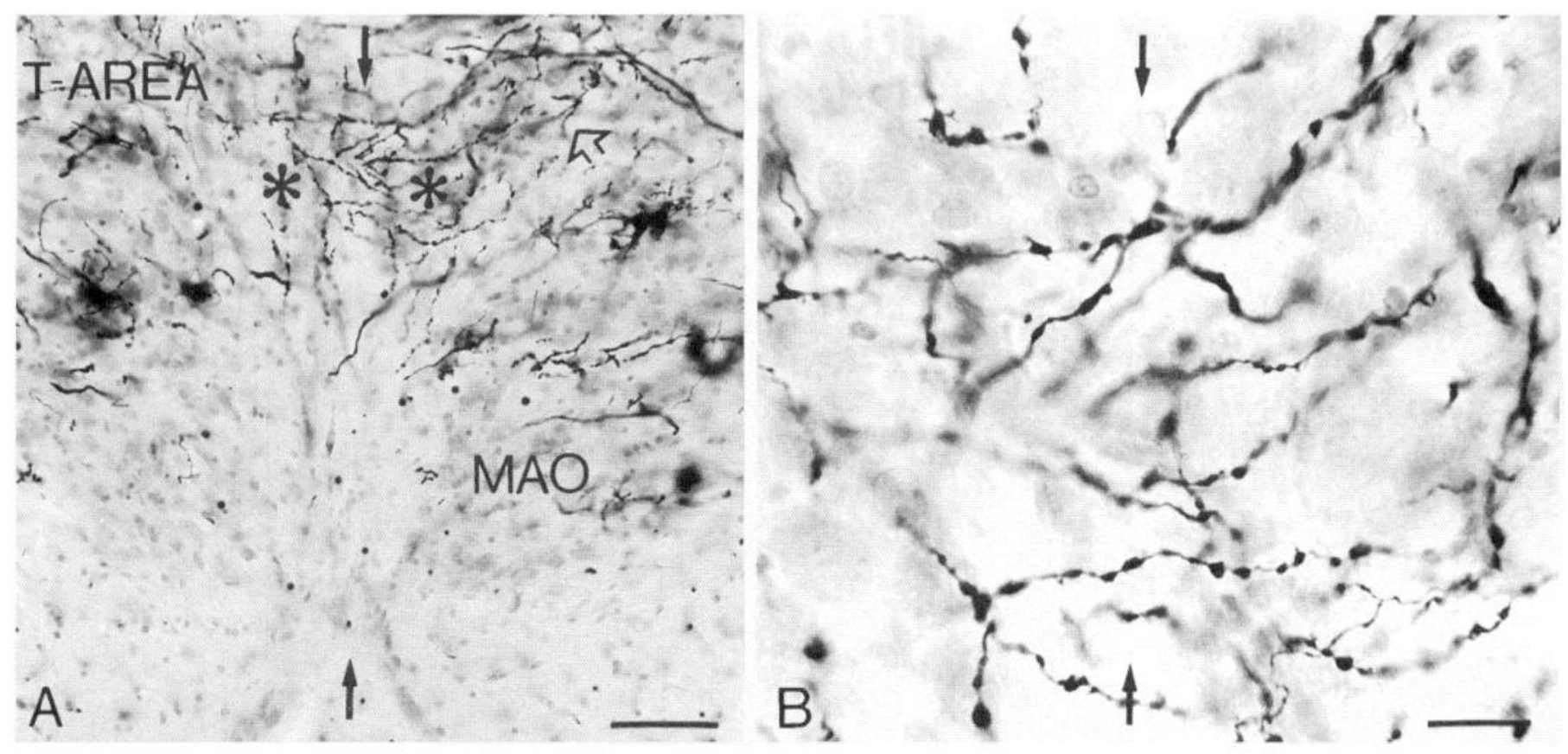

Figure 4. A, Micrograph of the left and right DMCC (asterisks) from a Golgi-impregnated section of the rat brainstem. The dendrites course from one side to the other, and they even traverse from the DMCC to adjacent olivary subdivisions (open arrow). Black arrows indicate midline, and $T$ - $A R E A$ indicates transition area between principal olive and dorsal accessory olive. $B$, High-power micrograph of the midline between left and right DMCC. $M A O$, Medial accessory olive. Scale bars: $A, 100 \mu \mathrm{m} ; B, 25 \mu \mathrm{m}$.

of the olivary dendrites as revealed by the Golgi-staining and labeling of the dendritic lamellar bodies. (1) The only midline area with a continuum of GAD-immunoreactive terminals was the area where the left and right DMCC fused (Fig. 6), and (2) the distribution of GAD-labeled terminals in the DMCC extended into the medial accessory olive and into the T-area. Figure $6 A$ and $B$ illustrates that both continuums, the one on the midline and the one with the adjacent olivary subdivisions, are located partly at different rostrocaudal levels. The GABA-labeling in the DMCC was relatively dense compared with that in adjacent olivary subdivisions.

\section{Electron microscopy}

Ultrastructural analysis of the DMCC verified the light microscopic observations that its midline region contains cell bodies from which the dendrites traverse to both olives and that some dendrites in this region cross from one side to the other. The DMCC, including its midline region and its border areas with the adjacent olivary subdivisions, contained many glomeruli that incorporated dendritic spines linked by gap junctions (Fig. 7A,B). Compared with the glomeruli of the adjacent olivary subdivisions, those in the DMCC were relatively complex and included many dendritic elements, often more than seven. Analysis of the electron microscopic material processed for GABA-immunocytochemistry demonstrated that glomerular dendrites linked by gap junctions were contacted by GABAergic terminals (Fig. 7C). The dendritic lamellar bodies were located mostly in the thick parts of the olivary dendrites that were situated in the immediate vicinity of the glomeruli (Fig. 7A). As observed in other subdivisions (De Zeeuw et al., 1995a), the ratio of the number of dendritic lamellar bodies to the number of gap junctions in the DMCC was $\sim 1(0.96)$.

\section{Multiple electrode recording}

Bilateral multiple electrode recordings of CS activity were obtained simultaneously from lobule IXb and crus IIA to corrobo- rate the anatomical findings. Bilateral recordings were obtained from lobule IXb because the DMCC projects to this region of the cerebellar cortex (Eisenman, 1984; Apps, 1990), and therefore bilateral synchronization of CS activity should occur in this cerebellar cortical region, because cells of the left and right DMCC are coupled electrotonically via dendrodendritic gap junctions. Furthermore, the degree of synchronization of CS activity between crus IIA and lobule IXb was investigated because our anatomical findings demonstrated dendrodendritic gap junctions connecting cells of the DMCC and T-area of the IO.

Averaged across the experiments of all three rats, the lobule IXb CS had a mean firing rate of $0.84 \pm 0.05 \mathrm{~Hz}$, which was significantly less than $(p<0.01)$ the $1.26 \pm 0.15 \mathrm{~Hz}$ (mean \pm SEM) mean firing rate found for crus IIA Purkinje cells. The mean CS firing rate for crus IIA Purkinje cells was $147 \%$ of that for the lobule IXb cells. The lower mean spontaneous firing rates found for vermal CS activity were consistent with our anatomical findings of a denser GABAergic input to the DMCC than to the regions of the IO that project to crus IIA.

In all animals, a significant but relatively low degree of intermittent CS synchrony was present between the left and right lobules IXb. Averaged across all possible cell pairs having one cell on each side of the vermis $(n=726)$, the zero-time autocorrelation coefficient was $0.0029 \pm 0.0002$, which is comparable to levels of interhemispheric synchrony observed between the two crura IIA (Lang et al., in press). Systemic injections of picrotoxin, a $\mathrm{GABA}_{\mathrm{A}}$ antagonist (Bormann, 1988), led to significant increases in CS synchrony among lobule IXb cells, both within a single side and bilaterally.

The spatial distribution of bilateral CS synchrony in crus IIA and lobule IXb is shown in Figure 8. Each circle represents the relative position of the electrode on the surface of the cerebellum, and the area of each circle is proportional to the degree of synchrony between the CSs of the selected master cell $(M)$ and 


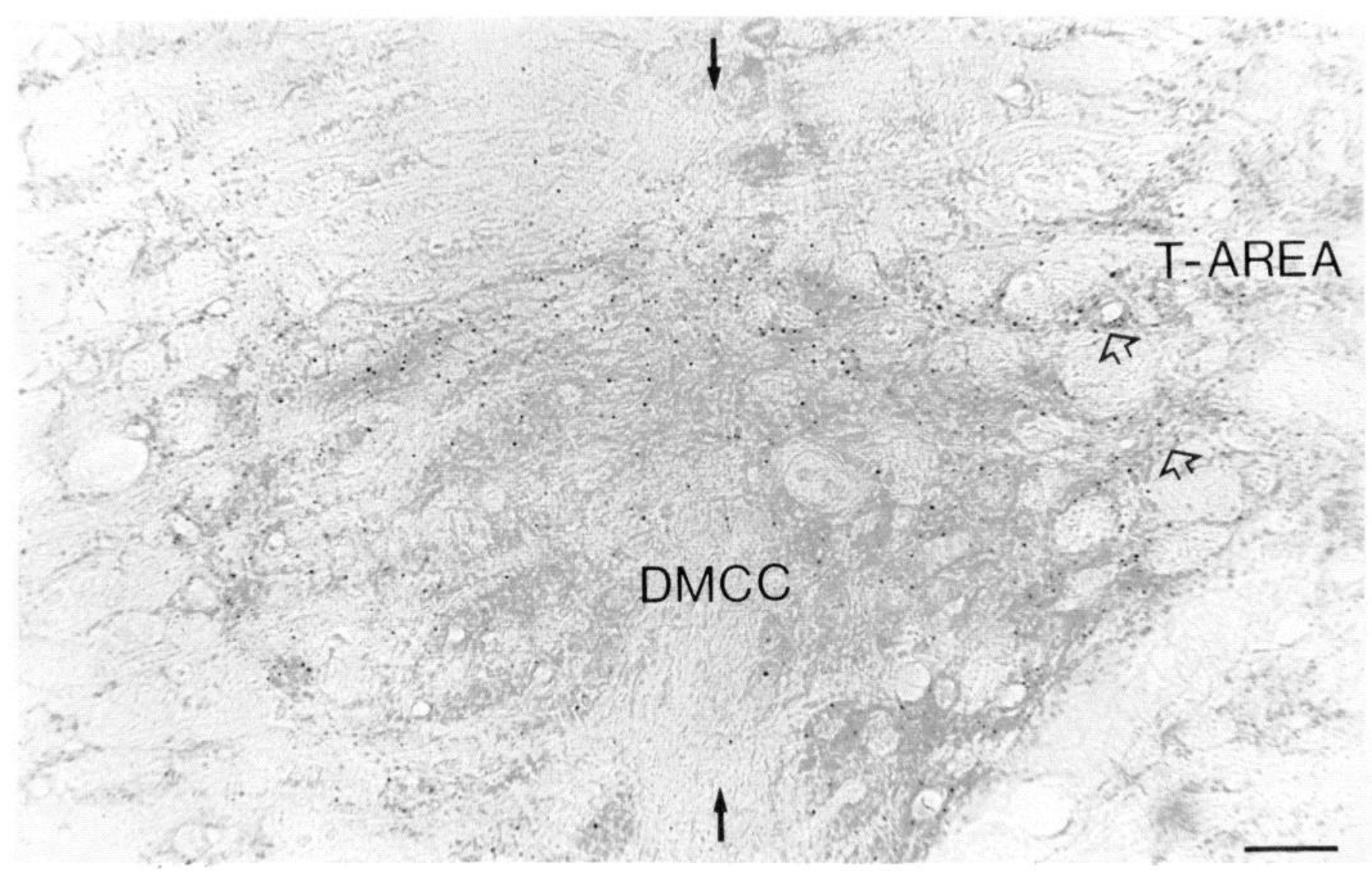

Figure 5. Micrograph of the DMCC in a section processed for immunocytochemistry with antiserum $\alpha 12 \mathrm{~B} / 18$, which detects specifically dendritic lamellar bodies; each dot corresponds to one dendritic lamellar body (De Zeeuw et al., 1995a). Note that the lamellar bodies were distributed most prominently in the periphery of the DMCC. Black arrows indicate midline, and open arrows indicate the continuity between DMCC and $T$-AREA. Scale bar, $17 \mu \mathrm{m}$.

those of the Purkinje cell recorded at that position (Llinás and Sasaki, 1989). During spontaneous activity (Fig. 8B), intermittent synchrony occurred between cell $\mathrm{M}$ and Purkinje cells within the same cerebellar lobule, as well as between cell $\mathrm{M}$ and Purkinje cells in each of the other lobules. Note that synchronization was greatest between cell $\mathrm{M}$ and the right crus IIA Purkinje cells located in the same parasagittal plane as cell $\mathrm{M}$, confirming previous results (Sasaki et al., 1989; Llinás and Sasaki, 1989). Note also that the synchrony in the contralateral hemisphere, although not as sharply defined, also has a spatial distribution with the more laterally located cells having a greater degree of synchronization with the laterally located cell $\mathrm{M}$.

Similar results were obtained when the correlation coefficients were averaged within and between all cells per lobule (Table 1A). First, all coefficients were significantly $>0$ (two-tailed $t$ test, $p<$ 0.01 ), indicating that synchrony occurred within and between all lobules. Second, all mean intralobular synchrony levels (indicated by the entries along the diagonal of Table 1A) were greater than the mean interlobular synchrony levels (indicated by the offdiagonal entries). Consistent with a stronger GABAergic innervation of the DMCC, the synchrony levels within the vermal areas were smaller than those within the crura IIA. By reading down each column or across each row in Table 1A, one can look at the synchrony values between cortical regions of increasing separation in terms of their olivary projection areas. Generally, the synchrony values decreased monotonically with increasing separation.

The results of a systemic injection of picrotoxin on CS syn- chrony can be seen in Figure $8 C$ and Table 1B. Large increases from control values were seen throughout the recording sites. Again consistent with the anatomical results, the intraregional increases relative to control for the vermal regions (3.62- and 3.11-fold) were higher than those for the crus IIA folia (2.81- and 1.30 -fold). Local injections of picrotoxin in the olive evoke the same effects on CS synchrony as systemic injections (Lang et al., in press); however, because it is technically difficult to place these injections exactly on the midline and because the spread of the drug will never be as symmetrical as after a systemic injection, the bilateral synchrony will be organized more asymmetrically after a local injection.

\section{DISCUSSION}

The present study was undertaken to determine the morphological basis for the bilateral synchrony of CS activity in the cerebellar cortex as discovered by Fukuda et al. (1987) and Lang et al. (in press). We provide evidence that the bilateral synchrony can be explained by bilateral afferents and by direct dendrodendritic coupling but not by interolivary axonal projections.

\section{Sources of bilateral synchrony in crus IIA: bilateral afferents}

The climbing fibers innervating crus IIA originate mainly from the transition area between the dorsal accessory olive and the principal olive (Llinás and Sasaki, 1989), which has been referred to as the T-area. Major sources of afferents innervating the T-area are 


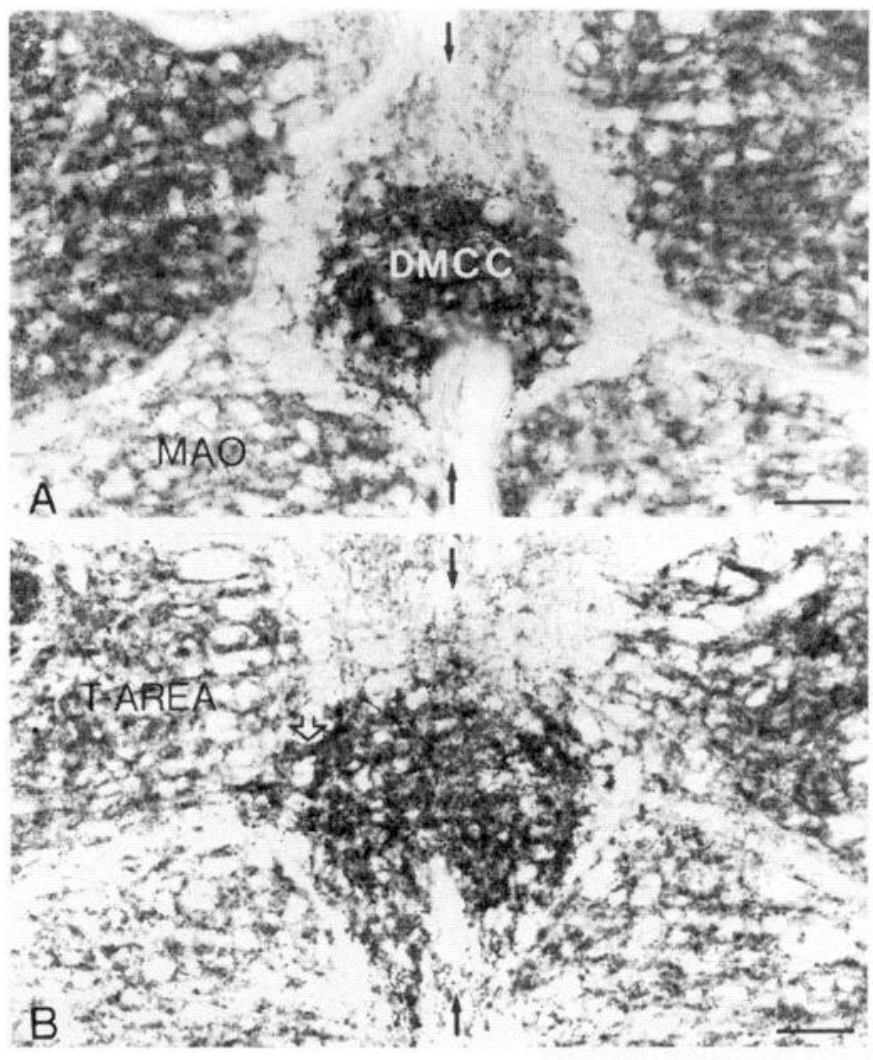

Figure 6. Micrographs of the DMCC in sections processed for immunocytochemistry with antiserum against GAD. The $D M C C$ in $A$ is totally separated from the adjacent subdivisions. $B$, At a more rostral level, the DMCC is continuous with the T-AREA (open arrows) and the medial accessory olive $(M A O)$. In both sections, it is evident that the GABAergic input to the DMCC is more prominent than the adjacent subdivisions. Black arrows indicate midline. Scale bars: $A, 85 \mu \mathrm{m} ; B, 90 \mu \mathrm{m}$.

the spinal trigeminal nucleus and dorsolateral hump of the cerebellar nuclei (Huerta et al., 1983, 1985; Ruigrok and Voogd, 1990). The projection to the T-area from the trigeminal nucleus is probably excitatory (Gellman et al., 1983; Weiss et al., 1993), whereas the projection from the central cerebellar nuclei, including that from the dorsolateral hump, is GABAergic (De Zeeuw et al., 1988, 1989, 1994b; Fredette and Mugnaini, 1991). With the use of PHA-L anterograde tracing, both projections were found to be bilateral and symmetrically organized. The ipsilateral component of the trigemino-olivary projection may not have been clear in the material of Huerta et al. (1983, 1985), who used tritiated amino acids and horseradish peroxidase as tracers. The labeling obtained with these substances does not provide a distinct visualization of varicosities and therefore would not be helpful in distinguishing labeled trigeminal terminals in the ipsilateral IO from labeled fibers of passage on their way to the contralateral IO.

The possible role of the bilateral trigeminal afferents of the IO in controlling the bilateral synchrony in crus IIA may not be as prominent as that of the stronger bilateral projection to the IO from the dorsolateral hump of the cerebellar nuclei. The involvement of this latter projection in the bilateral synchrony is supported by the observation by Lang et al. (in press) that synchrony between CS activity in crus IIA on the left and right increases after unilateral lesions of the central cerebellar nuclei. The GABAergic input from the dorsolateral hump to the IO probably controls the electrotonic coupling and thereby the extent of the synchrony between the olivary neurons (Llinás and Sasaki, 1989; De Zeeuw et al., 1989; Ruigrok and Voogd, 1995; Lang et al., in press). Thus, it is not surprising that the bilateral cerebellar GABAergic input of the IO and the interolivary-coupled dendrites (see below) both emerge in the present study as the two most likely morphological candidates controlling and underlying bilateral synchrony. At the same time, it may not be coincidental that both the inhibitory and the excitatory projections are bilateral. In fact, serial reconstructions of GABAergic terminals on intracellularly labeled olivary neurons demonstrated that all dendritic and axonal spines, including those that are coupled by gap junctions, receive both a GABAergic and an excitatory synaptic input (De Zeeuw, 1990; De Zeeuw et al., 1990b,c,d). Because the integrative time constant of excitable spines that receive a combined excitatory and inhibitory input is extremely sensitive to the timing between these inputs (Segev and Rall, 1988), we have proposed (De Zeeuw et al., 1990c) that the olivary spines serve as the interlocking gears of the olivary clockwork that may function as a timing device for motor behaviour (Llinás, 1989; Llinás and Sasaki, 1989; Lang, 1995; Welsh et al., 1995).

\section{Sources of bilateral synchrony in crus IIA: interolivary dendrodendritic coupling}

The neuropil of the left and right IO in the rat was demonstrated to be connected in the DMCC (Fig. 9). Examination of Golgiimpregnated material and sections immunostained for dendritic lamellar bodies demonstrated that olivary dendrites in the DMCC cross from one side to the other and from the DMCC to adjacent olivary subdivisions via the T-area. The ultrastructural analysis confirmed these findings and demonstrated that these dendrites are coupled by gap junctions. Moreover, a major afferent of these coupled dendrites, their GABAergic input, showed the same distribution pattern. These morphological observations were supported by simultaneous bilateral multiple-unit recordings from the crus IIA folia and the projection zones of the DMCC in lobule IXb. These experiments showed that Purkinje cells from all four regions can fire in synchrony and that this synchrony is particularly prominent after administration of the GABA-antagonist picrotoxin. The possibility that different olivary subdivisions from both sides are indeed electrotonically connected is supported by previous bilateral recordings from crus IIA and the demonstration that crossed inferior olivary reflexes in crus IIA can be obtained from stimulation in the cerebellar cortex of the contralateral crus IIA (Fukuda et al., 1987; Lang et al., in press). Taken together, the morphological and physiological findings demonstrate that the main subdivisions of the left and right IO are connected with each other through coupled dendrites that pass through the DMCC. Therefore, direct dendrodendritic coupling probably contributes to the bilateral synchrony observed in the rat cerebellar cortex.

\section{Absence of interolivary axonal connections}

Other possible explanations for the bilateral synchrony that were considered included interolivary axonal projections and olivary axons that are coupled through gap junctions. The possibility that olivary neurons provide collaterals to the contralateral side was investigated by tracing olivary axons labeled with BDA. None of these axons, which were labeled from the principal olive and dorsal and medial accessory olive up to the entrance of the contralateral restiform body, gave rise to collaterals. The Golgiimpregnated olivary axons also did not contain any collaterals. Previous light microscopic and electron microscopic studies of the normal IO of adult mammals using Golgi impregnation, intracellular injections, or anterograde tracing of PHA-L agree with the 


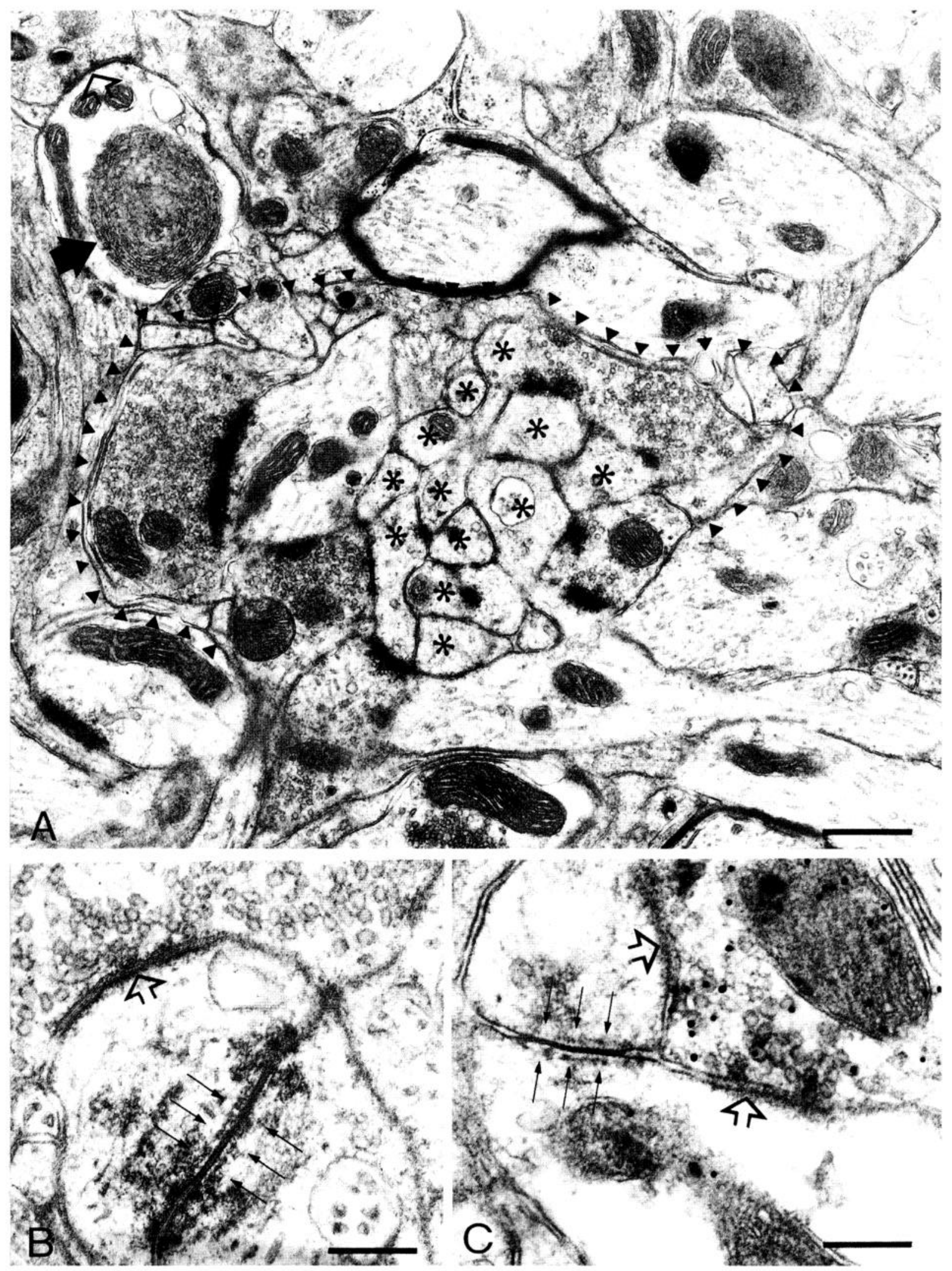

Figure 7. Electron micrographs from the midline area in the DMCC $(A, B)$ and the continuum between the DMCC and the T-area $(C) . A, \mathrm{~A}$ complex glomerulus in the DMCC includes many dendritic elements (asterisks). Note that the dendritic lamellar body (black arrow) is located just outside the glomerulus delineated by the arrowheads. $B$, Higher magnification of a gap junction (thin arrows) in the midline area of the DMCC. $C$, A GABAergic terminal labeled with postembedding immunogold is apposed to dendritic spines coupled by a gap junction (thin arrows). Open arrows indicate symmetric synapses. Scale bars: $A, 0.8 \mu \mathrm{m} ; B, 0.18 \mu \mathrm{m} ; C, 0.28 \mu \mathrm{m}$. 


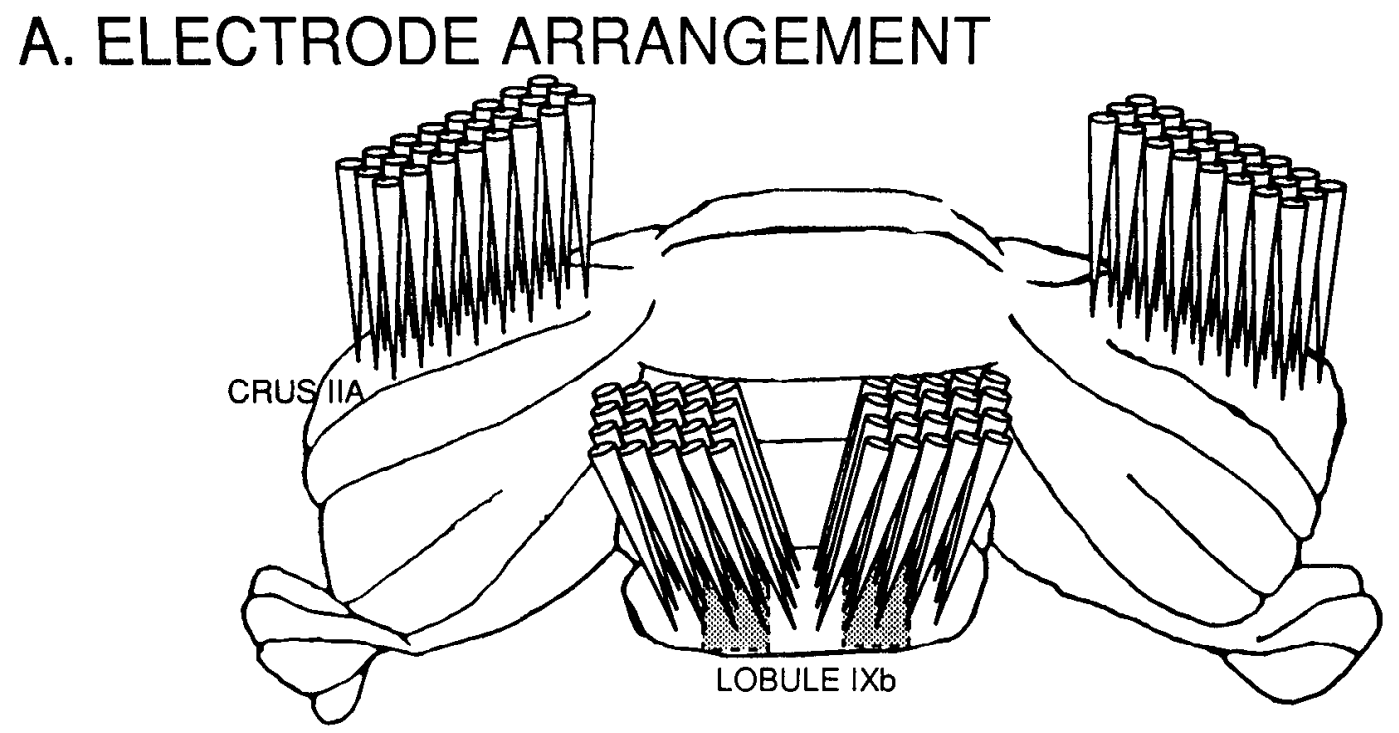

\section{B. SPONTANEOUS}

RIGHT

CRUS IIA

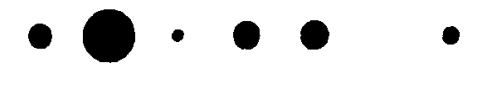

VERMAL

LOBULE IXb
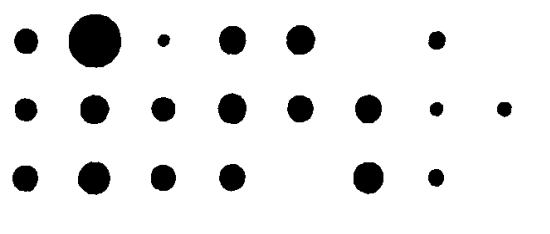

\section{PICROTOXIN}

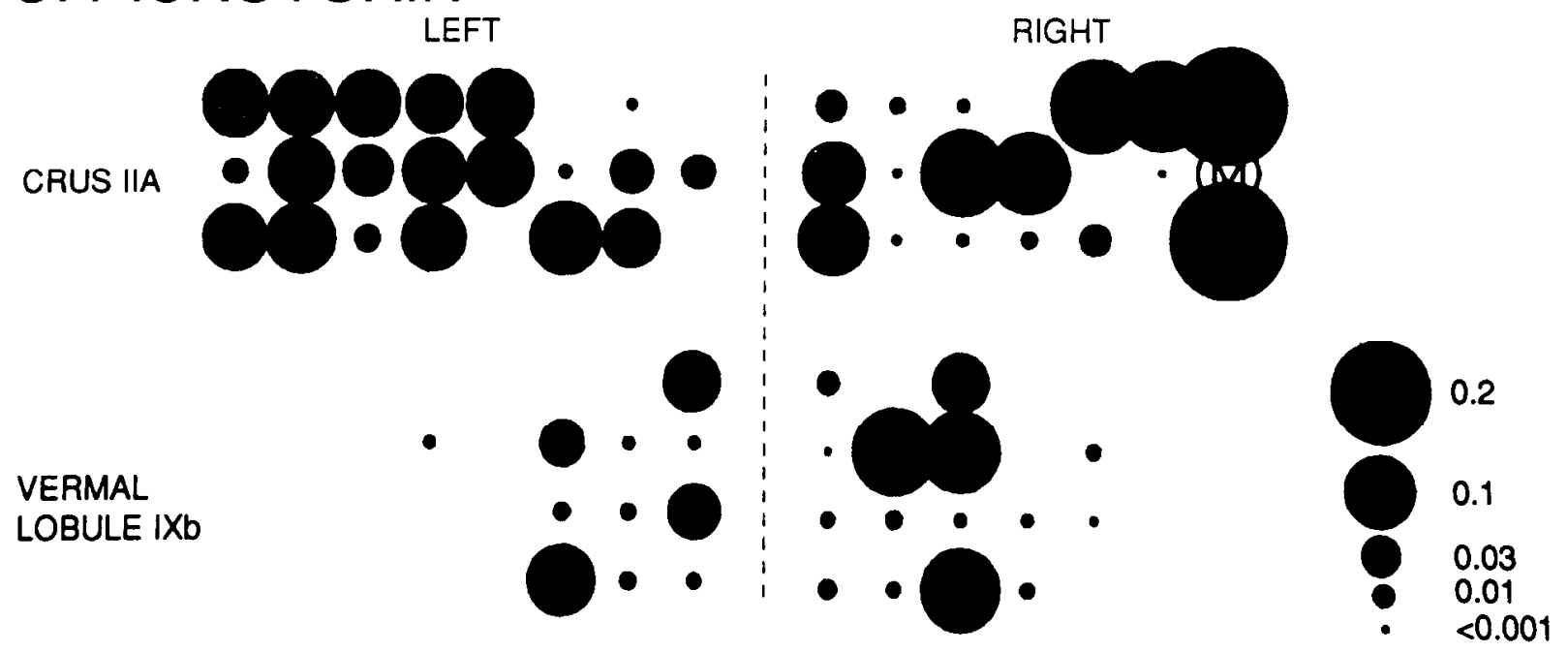

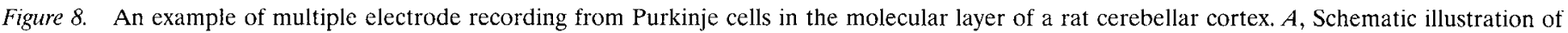

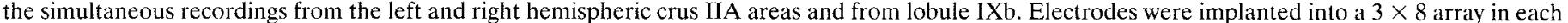

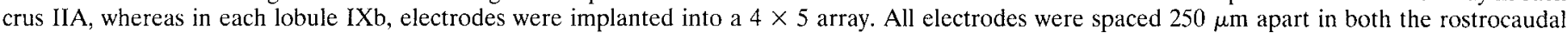

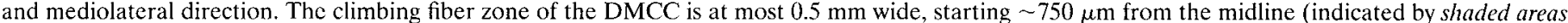

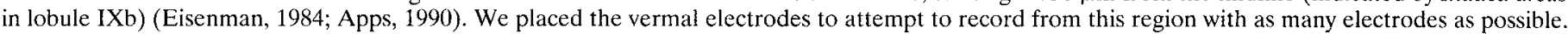


Table 1. Synchrony coefficients within and between all cells per lobule

\begin{tabular}{llll} 
Group of neurons & Left crus IIA & Left lobule IXb & Right lobule IXb \\
\hline $\begin{array}{l}\text { A. Spontaneous activity } \\
\text { Left crus IIA }\end{array}$ & $0.0361 \pm 0.0035$ & & \\
Left lobule IXb & $0.0047 \pm 0.0006$ & $0.0086 \pm 0.0022$ & $0.0229 \pm 0.0064$ \\
Right lobule IXb & $0.0015+0.0002$ & $0.0030 \pm 0.0007$ & $0.0031 \pm 0.0005$ \\
Right crus IIA & $0.0069 \pm 0.0002$ & $0.0022 \pm 0.0002$ & \\
& & & \\
B. Activity after picrotoxin & $0.1015 \pm 0.0068$ & & \\
Left crus IIA & $0.0276 \pm 0.0019$ & $0.0311 \pm 0.0072$ & $0.0712 \pm 0.0139$ \\
Left lobule IXb & $0.0293 \pm 0.0027$ & $0.0350 \pm 0.0043$ & $0.0302 \pm 0.0030$ \\
Right lobule IXb & $0.0389 \pm 0.0018$ & $0.0229 \pm 0.0019$ & 0.0056 \\
Right crus IIA & & &
\end{tabular}

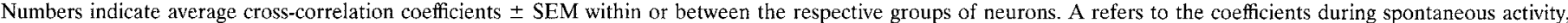
whereas $\mathrm{B}$ refers to the coefficients after systemic administration of picrotoxin. All corresponding values between $\mathrm{A}$ and $\mathrm{B}$ are significantly different (all $p$ values $<0.01$ ).

present findings (Ramon y Cajal, 1909; Scheibel and Scheibel, 1955; Scheibel et al., 1956; Walberg, 1963; Sotelo et al., 1974; King, 1980; Rutherford and Gwyn, 1980; Foster and Peterson, 1986; De Zeeuw et al., 1989, 1990b, 1993; Ruigrok et al., 1990a; Sugihara et al., 1993). Olivary axons collaterals have been found only occasionally in the IO of young kittens (Ramon y Cajal, 1909) and in the hypertrophic IO of adult cats (De Zeeuw et al., 1990a; Ruigrok et al., 1990b).

Another possibility that should be considered is that olivary axons themselves may be coupled by gap junctions. This possibility results from the observation that olivary axons give rise to spines that together with the coupled dendritic spines are incorporated in the glomeruli (De Zeeuw et al., 1990b). Because these axonal spines originate only from the axon hillock and because gap junctions have not been observed at nodes of Ranvier or other parts of olivary axons, however, it seems unlikely that interaxonal coupling plays a role in the bilateral synchrony. In sum, the available data strongly suggest that interolivary axonal connections, both in terms of contralateral projections and axonal coupling, do not play a substantial role in the bilateral synchrony of climbing fiber responses in the rat cerebellar cortex.

\section{Extent and strength of coupling}

The present study indicates that widely separated olivary neurons can fire in synchrony. This long-distance synchrony demonstrates the functional effectiveness of the coupling between olivary neurons and raises the question of how many dendrodendritic gap junctions are incorporated in the entire membrane of a single olivary neuron. In individual nonserial ultrathin sections of the $\mathrm{IO}$, the average ratio of the number of dendrodendritic gap junctions to the number of dendritic lamellar bodies is 0.93 (De Zeeuw et al., 1995a). The average density of lamellar bodies in the IO is 12.2 lamellar bodies/1000 $\mu^{2}$ in a given plane of focus, and 35 lamellar bodies $/ 10,000 \mu \mathrm{m}^{3}$ in 20 - $\mu$ m-thick immunostained sections. The total number of neurons in the $\mathrm{IO}$ (one side) and the total volume of the IO in the adult rat are 28,385 and $610,000,000$ $\mu \mathrm{m}^{3}$, respectively (Delhaye-Bouchaud, 1985). Thus, one rat IO contains 2,135,000 dendritic lamellar bodies and at least 1,985,550 gap junctions. Because each gap junction is always incorporated in the membranes of two olivary neurons (De Zeeuw et al., 1990d), each olivary neuron contains at least $140(2 \times 70)$ gap junctions. Because neuronal gap junctions are difficult to detect in the electron microscope, however, the experimentally observed ratio (0.93) of the number of dendrodendritic gap junctions to the number of dendritic lamellar bodies is underestimated (De Zeeuw et al., 1995a). The characteristic $2 \mathrm{~nm}$ intermembraneous space of a neuronal gap junction can be observed only if the 50 -nm-thick ultrathin section is cut perfectly perpendicular to the membranes of the gap junction plaque. Therefore, it is reasonable to assume that the total number of gap junctions per neuron is at least 5 to 10 times higher (700-1400). Because the total number of neurons positioned within the dense globular part of a dendritic tree is $\sim 115$ in the cat IO (Ruigrok et al., 1990a), the total average number of gap junctions between any given pair of cells must be between 6 and 12 .

Similar numbers can be obtained from calculations based on simultaneous intracellular recordings of olivary neurons in vitro (see Appendix). In a study by Llinás and Yarom (1981a), a current injection of $0.5 \mathrm{nA}$ produced a $10 \mathrm{mV}$ potential in an injected cell and a $2.5 \mathrm{mV}$ potential in an electrotonically coupled cell (Fig. 10). Therefore, the upper limit for the total conductance between two olivary cells can be assumed to be $66.7 \mathrm{nS}$. Because one gap junction consists of $\sim 100$ channels, each with a conductance of $\sim 30 \mathrm{pS}$ (Moreno et al., 1994), the maximum number of gap junctions between two olivary neurons should be $\sim 22$. If we consider a more realistic situation, shown in Figure $10 B$ (with $x=$ 4 ), where each olivary neuron has a membrane conductance $\left(G_{m}\right)$ and is coupled to four other neurons (Benardo and Foster, 1986) by gap junctional conductances $\left(G_{j}\right)$, then we obtain a membrane resistance $\left(R_{m}=1 / G_{m}\right)$ of $40 \mathrm{M} \Omega$ and a gap junctional conductance of $8.3 \mathrm{nS}$, suggesting that only two to three gap junctions

The five columns of electrodes in lobule IXb werc positioned $\sim 0.5 \mathrm{~mm}, 0.75 \mathrm{~mm}, 1 \mathrm{~mm}, 1.25 \mathrm{~mm}$, and $1.5 \mathrm{~mm}$ from the midline. $B, C$, spatial distribution of synchrony during spontaneous activity and after systemic administration of picrotoxin, respectively. Represented here are the recordings of only those electrodes whose CS isolations were retained for the entire experiment $(n=64)$. The master cell $(M)$ used for the cross-correlation analysis presented in this illustration is the same in $B$ as in $C$. Average cross-correlation coefficients were calculated from analyses in which every cell served as a master cell for one analysis (for outcomes, see Table 1). The total number of CSs was 101.178 in $B$ (42.6 min of recording) and 277.412 in $C$ (41.4 min). Note that all four areas, including the DMCC zones, can fire in synchrony both during spontaneous activity and after application of picrotoxin. The diameters of the black circles correspond to the correlation coefficients between the individual cells and the master cell. 


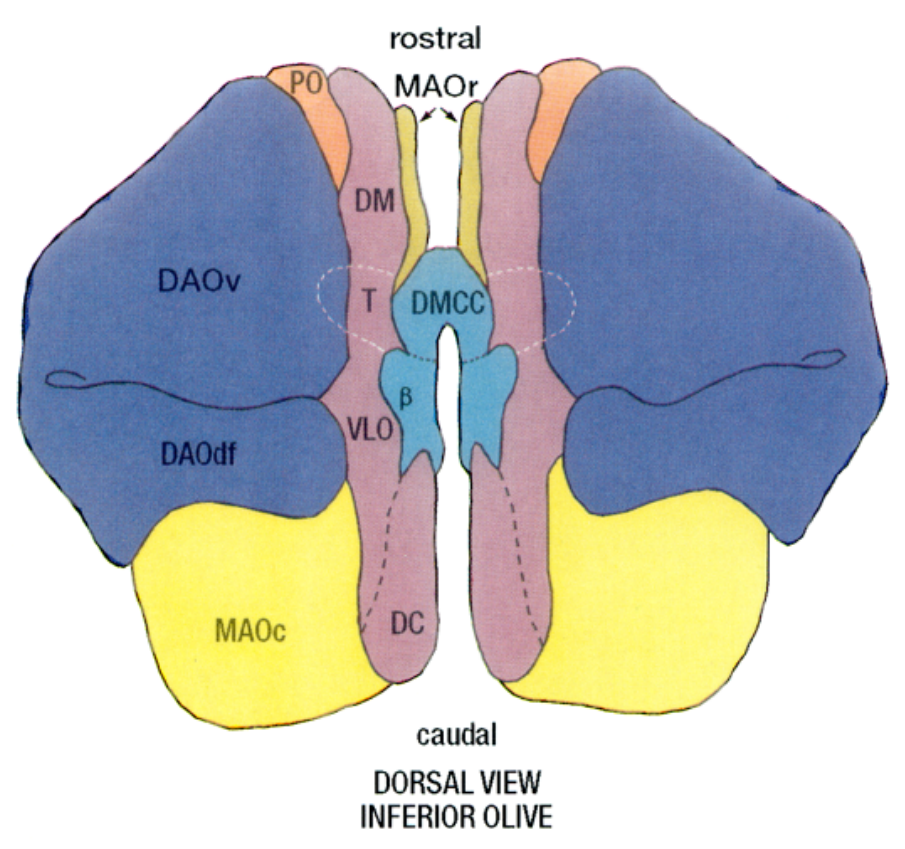

Figure 9. Diagram of the left and right rat IO that are connected in the middle via the DMCC and the T-area (indicated by dashed line). PO, principal olive; $M A O$, medial accessory olive; $D A O$, dorsal accessory olive; $D M$, dorsomedial group; $V L O$, ventrolateral outgrowth; $D C$, dorsal cap; $\beta$, $\beta$-nucleus (for definitions of olivary subdivisions, see Kooy, 1916; Brodal, 1940; Whitworth and Haines, 1986; Nelson and Mugnaini, 1988).

connect any two cells. The effect of varying " $x$ ", the number of cells coupled to cell 0 , is shown for three different values of membrane resistance in Figure $10 C$. The greater the $R_{m}$, the greater the maximum number of coupled neurons; thus for $R_{m}=$ $60 \mathrm{M} \Omega, 13$ cells at most could be coupled, whereas with an $R_{m}=$ $30 \mathrm{M} \Omega$, there is a maximum of only six cells.

The above calculations provide only estimates of the true extent of electrotonic coupling; however, both the anatomical and physiological data indicate that even though the number of gap junctions between any two olivary neurons may be relatively low, the total number of gap junctions present in an ensemble of olivary neurons must be substantial. Therefore, it is not surprising that electrotonic coupling in the IO is sufficient to synchronize olivocerebellar activity when required for the performance of coordinated movements (Welsh et al., 1995; Lang, 1995).

\section{Functional significance}

GAD-immunostained and Nissl-stained sections of the IO of human and other mammals such as cat, rabbit, and monkey do not show a continuum on the midline (Nelson et al., 1989), indicating that interolivary dendritic connections found in rats and also in mice (data not shown) cannot be considered a general finding. On the other hand, the bilateral projections to the IO from hindbrain areas like the cerebellar and vestibular nuclei and the nucleus prepositus hypoglossi also have been observed in several species other than rat (cat: Beitz, 1976; monkey: Kalil, 1979; rabbit: De Zeeuw et al., 1993). Specific studies will be needed to determine whether the bilateral afferents are sufficient to evoke bilateral synchrony in these mammals as well. This question may be particularly important for the olivary regions that are involved in the control of movements of midline structures in the head, such as those that project to crus IIA. Movements such as licking, swallowing, and biting require a complex and symmetric activation of bilateral musculature of different structures like the tongue and soft palate over a large set of motor domains (Welsh et al., 1995).

In rat, the direct coupling between the dendrites from both sides probably contributes to the bilateral synchrony, because synchrony was also demonstrated between two areas, i.e., crus IIA and lobule $\mathrm{IXb}$, which receive their climbing fibers from olivary neurons that are coupled by a series of dendrodendritic gap junctions but do not receive common afferents. By showing that the bilateral synchrony is attributable partly to a direct connection in the neuropil of the left and right IO (Fig. 9), we demonstrate to what extent electrotonic coupling between olivary neurons can play a role in their activity. The present findings imply that groups of olivary neurons located distantly from one another in different olivary subdivisions have the ability to oscillate and fire in synchrony, provided that the groups of neurons are connected through some pathway in the olivary neuropil (Llinás and Yarom, 1981a,b, 1986; Yarom, 1992). Whether the olivary neurons will actually fire in synchrony depends on the state of electrotonic coupling, which is regulated by the GABAergic input from the cerebellar and vestibular nuclei (Nelson et al., 1984; Sotelo et al., 1986; De Zeeuw et al., 1988, 1989; Angaut and Sotelo, 1989; Llinás and Sasaki, 1989; Lang et al., 1989, 1990; Sasaki et al., 1989; Fredette and Mugnaini, 1991; Lang et al., in press). These findings suggest that the concept that different olivary subdivisions are separate functional entities (Oscarsson, 1980) has to be modified in that all possible intrinsic pathways within the neuropil of the entire IO should be taken into consideration and the olivary compartments should be considered as dynamic states and not as purely anatomical structures (Llinás and Sasaki, 1989). This new insight may explain some recent, unexpected experimental results. For example, we recently demonstrated that some Purkinje cells in zones 2 and 4 of the rabbit flocculus can show climbing-fiber modulation during vestibular stimulation in the dark (De Zeeuw et al., 1995b), even though these climbing fibers are derived exclusively from the dorsal cap of the IO, which is known to receive visual signals from the nucleus of the optic tract (Tan et al., 1995). The vestibular signals to the IO are conveyed generally from the vestibular nuclei to the $\beta$-nucleus, but as far as is known presently, not directly to the dorsal cap (Barmack et al., 1989; De Zeeuw et al., 1993). Because the $\beta$-nucleus is continuous with the dorsal cap (Fig. $10)$, it is possible that the vestibular information is transmitted to some extent from the $\beta$-nucleus via coupled dendrites to the dorsal cap. Similarly, Welsh et al. (1995) demonstrated that different domains of Purkinje cells in crus IIA are activated synchronously, depending on the type of tongue movement that is being generated. These domains are dynamic in that they can overlap partly for one type of movement but not for another. Moreover, for some types of movements, the synchronously activated domains are not restricted to a single climbing-fiber zone, indicating that the synchronous activation of different olivary subdivisions is apparent not only after systemic administration of picrotoxin but also under physiological circumstances.

In sum, we conclude that the activity of neurons located remotely in different olivary subdivisions is coordinated in time and that the neurons in these different olivary subdivisions, controlled by their cerebellar GABAergic input, can function coherently.

\section{APPENDIX}

The values for the voltages in cell $0(10 \mathrm{mV})$ and cells 1 to $x(2.5$ $\mathrm{mV}$ ) and for $R_{T}(20 \mathrm{M} \Omega)$ (the experimentally determined total 


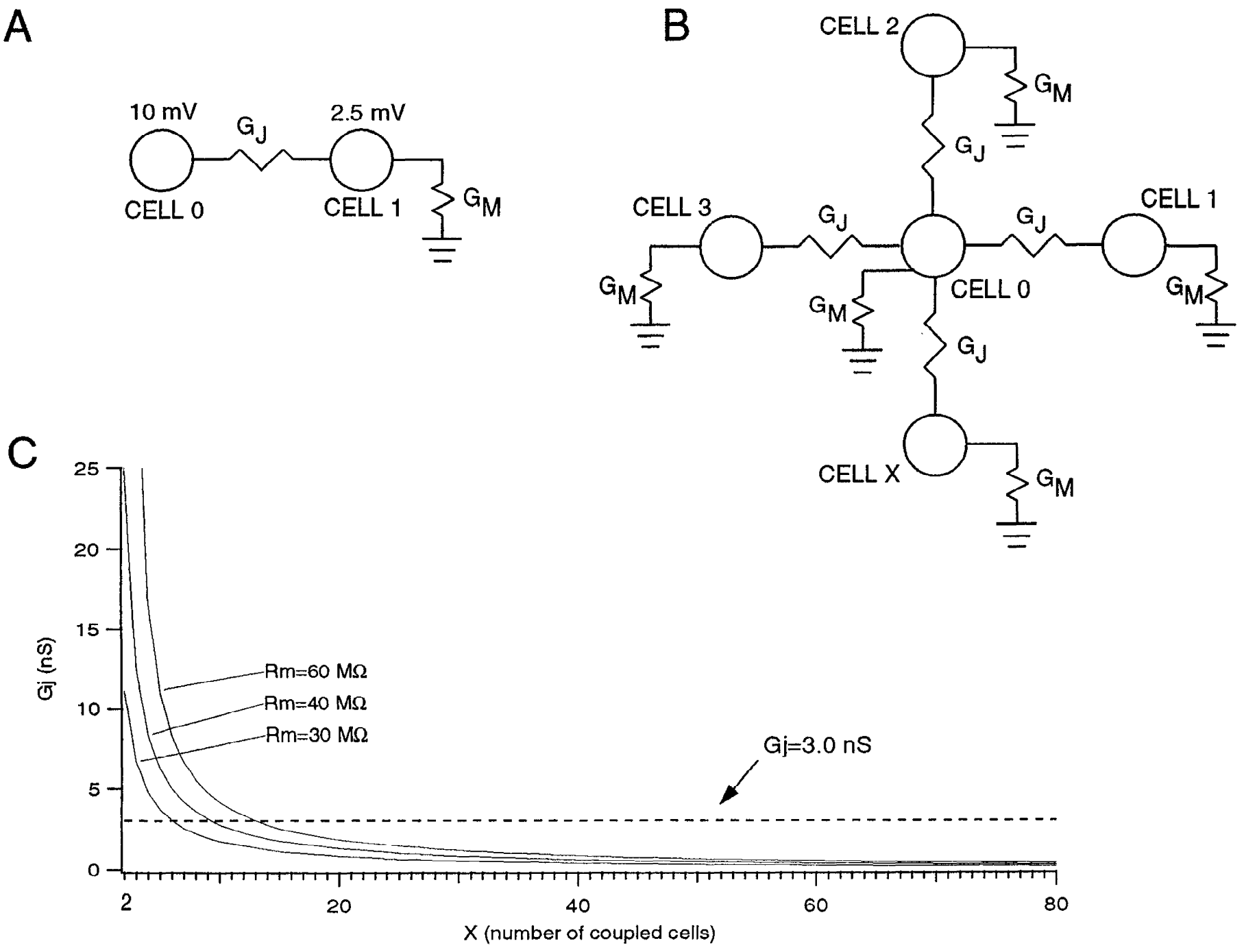

Figure 10. Estimate of number of gap junctions between IO neurons. $A$, Circuit showing cells 0 and 1 , which are coupled by a gap junctional conductance $\left(G_{j}\right)$. Circuit assumes all injected current flows through $G_{j}$ into cell $1 . B$, More realistic circuit showing cell 0 coupled to X; other neurons via identical junctional conductances $G_{j}$. All cells have membrane conductance $G_{m}$. In both $A$ and $B$, a $0.5 \mathrm{nA}$ current pulse into cell 0 produces a $10 \mathrm{mV}$ response in that cell and a $2.5 \mathrm{mV}$ response in cells 1 through X (values based on Fig. 9 of Llinás and Yarom, 1981a). If we assume that all the injected current flowed through the gap junctional conductance (i.e., no current was lost through the membrane of cell 0 ), then using Ohm's law we can calculate an upper limit for the total conductance between the two cells of $0.5 \mathrm{nA} /(10 \mathrm{mV}-2.5 \mathrm{mV})=66.7 \mathrm{nS}$. $C$, Plot of $G_{j}$ versus X for three values of $R_{m}$. Dashed line indicates $3.0 \mathrm{nS}$, the estimated conductance of a single gap junction. The point at which each curve crosses this line gives an estimate of the maximum number of coupled cells to cell 0.

resistance of an olivary neuron, which is composed of both the membrane and the gap junctional resistances) were based on the results of Llinás and Yarom (1981a). Using these values, $R_{m}$ and $R_{j}$ can be solved for using Equations $1-4$ below, which characterize the circuit shown in Figure $10 B$ when $x=4$ :

$$
\begin{gathered}
I_{\text {in }}=0.5 \mathrm{nA}=4 * I_{j}+I_{m} \\
10 \mathrm{mV}=I_{m}{ }^{*} R_{m} \\
7.5 \mathrm{mV}=I_{J}^{*} R_{J} \\
\left(1 / R_{T}\right)=\left(1 / R_{m}\right)+\left(4 /\left(R_{j}+R_{m}\right)\right)
\end{gathered}
$$

Solving equations 2,3 , and 4 for $I_{m}, I_{j}$, and $R_{j}$, respectively, and substituting into Equation 1 gives:

$0.5 \mathrm{nA}=\left[30 \mathrm{mV}\left(R_{m}-R_{T}\right) /\left(5^{*} R_{m}{ }^{*} R_{T}-R_{m}{ }^{2}\right)\right]+\left(10 \mathrm{mV} / R_{m}\right)$
Rearranging gives:

$$
R_{m}{ }^{2}-60 \mathrm{M} \Omega^{*} R_{m}-8 \times 10^{14} \Omega^{2}=0
$$

Solving the quadratic gives $R_{m}=40 \mathrm{M} \Omega$ or $R_{m}=20 \mathrm{M} \Omega$. We can reject the latter root because it produces a negative value for $R_{j}$ when substituted into Equation 4. The first root for $R_{m}$ produces a value of $120 \mathrm{M} \Omega$ for $R_{j}$, or a conductance of $8.3 \mathrm{nS}$.

If we let $x$, the number of coupled cells, vary, then Equation 4 becomes:

$$
\left(1 / R_{T}\right)=\left(1 / R_{m}\right)+\left(x /\left(R_{j}+R_{m}\right)\right)
$$

The curves in Figure $10 \mathrm{C}$ were generated by solving for $1 / R_{j}$ and setting $R_{m}$ equal to 30,40 , and $60 \mathrm{M} \Omega$.

\section{REFERENCES}

Adams JC (1979) A fast, reliable silver-chromate Golgi method for perfusion-fixed tissue. Stain Technol 54:225-226. 
Aggelopoulos NC, Duke C, Edgley SA (1994) Non-uniform conduction time in the olivocerebellar pathway in the anaesthetized cat. J Physiol (Lond) 476:26-27.

Angaut P, Sotelo C (1989) Synaptology of the cerebello-olivary pathway: double labeling with anterograde axonal tracing and GABA immunocytochemistry in the rat. Brain Res 479:361-365.

Apps R (1990) Columnar organisation of the inferior olive projection to the posterior lobe of the rat cerebellum. J Comp Neurol 302:236--254.

Azizi S, Woodward DJ (1987) Inferior olivary nuclear complex of the rat: morphology and comments on the principles of organization within the olivocercbcllar systcm. J Comp Ncurol 263:467-484.

Barmack NH, Mugnaini E, Nelson BJ (1989) Vestibularly-evoked activity of single neurons in the $\beta$-nucleus of the inferior olive. In: The olivocerebellar system in motor control (Strata P, ed). Exp Brain Res [Suppl] 17:313-323.

Beitz A (1976) The topographical organization of the olivo-dentate and dentato-olivary pathways in the cat. Brain Res 115:311-317.

Benardo LS, Foster RE (1986) Oscillatory behaviour in inferior olive neurons: mechanism, modulation, cell aggregates. Brain Res Bull 17:773-784.

Blackstad TW, Osen KK, Mugnaini E (1984) Pyramidal neurones of the dorsal cochlear nucleus: a Golgi and computer reconstruction study in the cat. Neuroscience 13:827-854.

Bormann $J$ (1988) Electrophysiology of $\mathrm{GABA}_{\mathrm{A}}$ and $\mathrm{GABA}_{\mathrm{B}}$ receptor subtypes. Trends Neurosci 11:112-116.

Bowman MH, King JS (1973) The conformation, cytology and synaptology of the opossum inferior olivary nucleus. J Comp Neurol 148:491-524.

Brodal A (1940) Experimentelle Untersuchungen uber die olivocerebellare Lokalisation. Z Gesante Neurol Psychiat 169:1-153.

Buijs RM, van Vulpen EHS, Geffard M (1987) Ultrastructural localization of GABA in the supraoptic nucleus and the neural lobe. Neuroscience 20:347-355

Delhaye-Bouchaud N, Geoffroy B, Mariani J (1985) Neuronal death and synapse elimination in the olivoccrcbcllar system. I. Cell counts in the inferior olive of developing rats. J Comp Neurol 232:299-308.

De Zeeuw CI (1990) Ultrastructure of the cat inferior olive. PhD thesis, Erasmus University.

De Zeeuw CI, Holstege JC, Calkoen F, Ruigrok TJH, Voogd J (1988) A new combination of WGA-HRP anterograde tracing and GABAimmunocytochemistry applied to afferents of the cat inferior olive at the ultrastructural level. Brain Res 447:369-375.

De Zeeuw CI, Holstege JC, Ruigrok TJH, Voogd J (1989) An ultrastructural study of the GABAergic, the cerebellar and the mesodiencephalic innervation of the cat medial accessory olive: anterograde tracing combined with immunocytochemistry. J Comp Neurol 284:12-35.

De Zeeuw CI, Ruigrok TJH, Schalekamp MPA, Boesten AJP, Voogd J (1990a) Ultrastructural study of the cat hypertrophic inferior olive following anterograde tracing, immunocytochemistry, and intracellular labeling. Eur J Morphol 28:240-255.

De Zeeuw CI, Ruigrok TJH, Holstege JC, Schalekamp MPA, Voogd J (1990b) Intracellular labeling of neurons in the medial accessory olive of the cat. III. Ultrastructure of the axon hillock and initial segment and their GABAergic innervation. J Comp Neurol 300:495-510.

De Zeeuw CI, Holstege JC, Ruigrok TJH, Voogd J (1990c) Mesodiencephalic and cerebellar terminals end upon the same dendritic spines within the glomeruli of the cat and rat inferior olive: an ultrastructural study using a combination of $\left({ }^{3} \mathrm{H}\right)$ leucine and WGA-HRP anterograde tracing. Neuroscience 34:645-655.

De Zeeuw CI, Ruigrok TJH, Holstege JC, Schalekamp MPA, Voogd J (1990d) Intracellular labeling of neurons in the medial accessory olive of the cat. III. Ultrastructure of dendritic spines and their GABAergic innervation. J Comp Neurol 300:478-495.

De Zeeuw CI, Wentzel P, Mugnaini E (1993) Fine structure of the dorsal cap of the inferior olive and its GABAergic and non-GABAergic input from the nucleus prepositus hypoglossi in rat and rabbit. J Comp Neurol 327:63-82.

De Zeeuw CI, Wylie DR, DiGiorgi PL, Simpson JI (1994a) Projections of individual Purkinje cells of identified zones in the flocculus to the vestibular and cerebellar nuclei in the rabbit. $J$ Comp Neurol 349:428-448.

De Zeeuw CI, Gerrits NM, Voogd J, Lconard CS, Simpson JI (1994b) The rostral dorsal cap and ventrolateral outgrowth of the rabbit inferior olive receive a GABAergic input from dorsal group y and the ventral dentate nucleus. J Comp Neurol 341:420-432.
De Zeeuw CI, Hertzberg EL, Mugnaini E (1995a) The dendritic lamellar body: a new neuronal organelle putatively associated with dendrodendritic gap junctions. J Neurosci 15:1587-1604.

De Zeeuw CI, Wylie DR, Stahl J, Simpson JI (1995b) Phase relations of floccular Purkinje cells during compensatory eye movements in the alert rabbit. J Neurophysiol 74:2051-2064.

Eccles JC, Llinás R, Sasaki K (1966) The excitatory synaptic action of climbing fibers on the Purkinje cells of the cerebellum. J Physiol (Lond) 182:268-296

Eisenman L (1984) Organization of the olivocerebellar projection to the uvula in the rat. Brain Behav Evol 24:1-12.

Flumerfelt BA, Hrycyshyn AW (1985) Precerebellar nuclei and red nucleus. In: The rat nervous system, pp 221-250. Australia: Academic.

Foster RE, Peterson BE (1986) The inferior olivary complex of guinea pig: cytoarchitecture and cellular morphology. Brain Res Bull 17:785-800.

Fredette BJ, Mugnaini E (1991) The GABAergic cerebello-olivary projection in the rat. Anat Embryol 184:225-243.

Fukuda M, Yamamoto T, Llinás R (1987) Simuitaneous recordings from Purkinje cells of different folia in the rat cerebellum and their relation to movement. Soc Neurosci Abstr 13:603.

Gellman R, Houk JC, Gibson AR (1983) Somatosensory properties of the inferior olive of the cat. J Comp Neurol 215:228-243.

Gerfen CR, Sawchenko PE (1984) An anterograde neuroanatomical tracing method that shows the detailed morphology of neurons, their axons and terminals: immunohistochemical localization of an axonally transported plant lectin, Phaseolus vulgaris leucoagglutinin (PHA-L) Brain Res 290:219-238.

Gerstein GL, Kiang WY (1960) An approach to the quantitative analysis of equations of electrophysiological data from single neurons. Biophys J $1: 15-28$.

Groenewegen HJ, Voogd J (1977) The parasagittal zonation within the olivo-cerebellar projection. I. Climbing fiber distribution in the vermis of cat cerebellum. J Comp Neurol 174:417-488.

Groenewegen HJ, Voogd J, Freedman SL (1979) The parasagittal zonation within the olivo-cerebellar projection. II. Climbing fiber distribution in the intermediate and hemispheric parts of cat cerebellum. J Comp Neurol 183:551-602.

Gwyn DG, Nicholson GP, Flumerfelt BA (1977) The inferior olivary nucleus of the rat: a light and electron microscopic study. J Comp Neurol 174:489-520.

Huerta MF, Frankfurter A, Harting JK (1983) Studies of the principal sensory and spinal trigeminal nuclei of the rat: projections to the superior colliculus, inferior olive and cerebellum. J Comp Neurol 220:147-167.

Huerta MF, Hashikawa T, Gayoso MJ, Harting JK (1985) The trigemino-olivary projections in the cat: contributions of individual subnuclei. J Comp Neurol 241:180-190.

Iwahori N, Kiyota E (1987) A Golgi study on the inferior olivary nucleus in the red sting ray, Dasyatis akajei. Neurosci Res 5:113-125.

Kalil K (1979) Projections of the cerebellar and dorsal column nuclei upon the inferior olive in the rhesus monkey: an autoradiography study. J Comp Neurol 188:43-62.

King JS (1980) The synaptic organization of the inferior olivary nucleus. In: The inferior olivary nucleus: anatomy and physiology. (Courville $\mathrm{J}$, de Montigny C, Lamarre Y, eds), pp 1-35. New York: Raven.

Kooy FH (1916) The inferior olive in vertebrates. PhD thesis, Haarlem: Erven Bohn.

Lang EJ (1995) Synchronicity, rhythmicity and movement: the role of the olivocercbellar system in motor coordination. PhD thesis, NYU Medical Center.

Lang EJ, Chou M, Sugihara I, Llinás R (1989) Intraolivary injection of picrotoxin causes reorganization of complex spike activity. Soc Neurosci Abstr 15:77.5.

Lang EJ, Sugihara I, Llinás R (1990) Lesions of the cerebellar nuclei, but not of mesencephalic structures alters the spatial pattern of complex spike synchronicity as demonstrated by multiple electrode recordings. Soc Neurosci Abstr 16:370.3.

Lang EJ, Sugihara I, Llinás R GABAergic modulation of complex spike activity by the cerebellar nucleo-olivary pathway in rat. J Neurophysiol, in press.

Llinás R (1974) 18th Bowditch Lecture: motor aspects of cerebellar control. Physiologist 17:19-46. 
Llinás R (1989) Electrophysiological properties of the olivo-cerebellar system. In: The olivo-cerebellar system in motor control (Strata P, ed). Exp Brain Res [Suppl] 17:201-209.

Llinás R, Yarom Y (1981a) Electrophysiology of mammalian inferior olivary neurons in vitro. Different types of voltage-dependent ionic conductances. J Physiol (Lond) 315:549-567.

Llinás R, Sasaki K (1989) The functional organization of the olivocerebellar system as examined by multiple Purkinje cell recordings. Eur J Neurosci 1:587-602.

Llinás R, Yarom Y (1981b) Properties and distribution of ionic conductances generating electroresponsiveness of mammalian inferior olivary neurones in vitro. J Physiol (Lond) 315:569-584.

Llinás R, Yarom Y (1986) Oscillatory properties of guinea-pig inferior olivary neurones and their pharmacological modulation: an in vitro study. J Physiol (Lond) 376:163-182.

Llinás R, Baker R, Sotelo C (1974) Electrotonic coupling between neurons in cat inferior olive. J Neurophysiol 37:560 -571.

Moreno AP, Brook M, Fishman GI, Spray DC (1994) Gap junction channels: distinct voltage-sensitive and insensitive conductance states. Biophys J 67:113-119.

Mugnaini E, Dahl AL (1983) Zinc-aldehyde fixation for lightmicroscopic immunocytochemistry of nervous tissues. J Histochem Cytochem 31:1435-1438.

Nelson B, Mugnaini E (1988) The rat inferior olive as seen with immunostaining for glutamic acid decarboxylase. Anat Embryol 179:109-127.

Nelson BJ, Adams JC, Barmack NH, Mugnaini E (1989) Comparative study of glutamate decarboxylase immunoreactive boutons in the mammalian inferior olive. J Comp Neurol 286:514-539.

Nelson B, Barmack NH, Mugnaini E (1984) A GABAergic cerebelloolivary projection in the rat. Soc Neurosci $A$ bstr 10:161.7.

Oertel WH, Schmechel DE, Tappaz ML, Kopin IJ (1981) Production of a specific antiserum to rat brain glutamic acid decarboxylase by injection of an antigen-antibody complex. Neuroscience 6:2689-2700.

Oscarsson O (1980) Functional organization of olivary projections to the cerebellar anterior lobe. In: The inferior olivary nucleus, anatomy and physiology (Courville J, de Montigny C, Lamarre Y, eds), pp 279-289. New York: Raven.

Ramon y Cajal S (1909-1911) Histologie du Système Nerveux de l'Homme et des Vertébrés. Vols. I and II. Paris: Maloine. Reprinted Madrid: Consejo Superior de Investigaciones Cientificas, 1952.

Ruigrok TJH, Voogd J (1990) Cerebellar nucleo-olivary projections in rat: an anterograde tracing study with Phaseolus vulgaris-leucoagglutinin (PHA-L). J Comp Neurol 298:315-333.

Ruigrok TJH, Voogd J (1995) Cerebellar influence on olivary excitability in the cat. Eur J Neurosci 7:679-693.

Ruigrok TJH, De Zeeuw CI, van den Burg J, Voogd J (1990a) Intracellular labeling of neurons in the medial accessory olive of the cat. I. Physiology and light microscopy. J Comp Neurol 300:458-477.

Ruigrok TJH, De Zeeuw CI, Voogd J (1990b) Hypertrophy of inferior olivary neurons: a degenerative, regenerative or plasticity phenomenon. Eur J Morphol 28:224-239.

Ruigrok TJH, Osse RJ, Voogd J (1992) Organization of inferior olivary projections to the flocculus and ventral paraflocculus of the rat cerebellum. J Comp Neurol 316:129-150.

Rutherford JG, Gwyn DG (1977) Gap junctions in the inferior olivary nucleus of the squirrel monkey, Saimiri sciureus. Brain Res $128: 374-378$.
Rutherford JG, Gwyn DG (1980) A light and electron microscopic study of the inferior olivary nucleus of the squirrel monkey, Saimiri sciureus. J Comp Neurol 189:127-155.

Sasaki K, Bower JM, Llinás R (1989) Multiple Purkinje cell recording in rodent cerebellar cortex. Eur J Neurosci 1:572-586.

Scheibel M, Scheibel A, Walberg F, Brodal A (1956) Areal distribution of axonal and dendritic patterns in inferior olive. J Comp Neurol $106: 21-50$

Scheibel ME, Scheibel AB (1955) The inferior olive: a Golgi study. J Comp Neurol 102:77-132.

Segev I, Rall W (1988) Computational study of an excitable dendritic spine. J Neurophysiol 60:499-523.

Seguela P, Geffard M, Buijs R, Le Moal M (1984) Antibodies against gamma-aminobutyric acid: specificity studies and immunocytochemical results. Proc Natl Acad Sci USA 81:3888-3892.

Sotelo C, Palay SL (1968) The fine structure of the lateral vestibular nucleus in the rat. I. Neurons and neuroglial cells. J Cell Biol 36:151-179.

Sotelo C, Llinás R, Baker R (1974) Structural study of inferior olivary nucleus of the cat: morphological correlates of electrotonic coupling. J Neurophysiol 37:541-559.

Sotelo C, Gotow T, Wassef M (1986) Localization of glutamic-aciddecarboxylase-immunoreactive axon terminals in the inferior olive of the rat, with special emphasis on anatomical relations between GABAergic synapses and dendrodendritic gap junctions. J Comp Neurol 252:32-50

Sugihara I, Lang EJ, Llinás R (1993) Uniform olivocerbellar conduction time underlies Purkinje cell complex spike synchronicity in the rat cerebellum. J Physiol (Lond) 470:243-271.

Swenson RS, Castro AJ (1983) The afferent connections of the inferior olivary complex in rats: an anterograde study using autoradiographic and axonal degeneration techniques. Neuroscience 8:259-275.

Szteyn S (1988) Types of neurons in nucleus olivaris inferior of the European bison. J Hirnforsch 29:353-356.

Tan J, Gerrits NM, Nanhoe RS, Simpson JI, Voogd J (1995) Zonal organization of the climbing fiber projection to the flocculus and nodulus of the rabbit: a combined axonal tracing and acetylcholinesterase histochemical study. J Comp Neurol 356:23-50.

Voogd J, Bigaré F (1980) Topographical distribution of olivary and corticonuclear fibers in the cerebellum. A review. In: The inferior olivary nucleus (Courville J, de Montigny C, Lamarre Y, eds), pp 207-235. New York: Raven.

Walberg F (1963) An electron microscopic study of the inferior olive of the cat. J Comp Neurol 12:1-18.

Weiss C, Disterhoft JF, Gibson AR, Houk JC (1993) Receptive fields of single cells from the face zone of the cat rostral dorsal accessory olive. Brain Res 605:207-213.

Welsh JP, Lang E, Sugihara I, Llinás R (1995) Dynamic organization of motor control within the olivocerebellar system. Nature 374:453-457.

Whitworth RH, Haines DE (1986) On the question of nomenclature of homologous subdivisions of the inferior olivary complex. Arch Ital Biol 124:271-317.

Wylie DR, De Zeeuw CI, Simpson JI (1995) Temporal relations of the complex spike activity of P-cell pairs in the vestibulocerebellum of rabbits. J Neurosci 15:2875-2887.

Yarom Y (1992) Electroneuronal hybridization: a novel approach to investigate rhythmogenesis in the inferior olivary nucleus. In: The cerebellum revisited (Llinás R, Sotelo C, eds), pp 201-213. New York: Springer. 